$16^{\text {th }}$ International Conference on

AEROSPACE SCIENCES \& AVIATION TECHNOLOGY,

ASAT - 16 - May 26 - 28, 2015, E-Mail: asat@ mtc.edu.eg

Military Technical College, Kobry Elkobbah, Cairo, Egypt

Tel : +(202) 24025292 - 24036138, Fax: +(202) 22621908

\title{
3D Range Sensors Capture, Transform and Modeling of Defects
}

\author{
M. Sedek ${ }^{*}$, A. Hammad ${ }^{\dagger}$, Mahmoud El-Nokrashy $^{\ddagger}$, Ahmed Abdelhafiz $^{\S}$, Farag Khodary ${ }^{\text {II }}$
}

\begin{abstract}
New developed technique is enhanced to recover 3D BIM (Three Dimensions Building Information Models) objects from 3D range surveying data by IR (Infra Red) camera or Laser Scanner for object defects observation. Defects detection and its characteristics have long played major role for condition and risk assessment of buildings. Defects photography by 3D range sensors from an external exposure station, if done mathematically, is useful for interpreting the photos taken by the sensors mounted at anywhere and pointed towards any parts of the building. In this paper an approach was developed to transform and 3D modeling of the buildings defects using multiple types of data and sensors. The advantage of this technique is the flexibility it provides to handle complex defects where a single technique is insufficient. The proposed approach is validated through Jacques Cartier Bridge case study were implemented on the design and inspection data and modeling the building defects by simplification the method of information visualization. Standing on the method, the Defect Information Model (DIM) is in its real shape, which decreases the difficulty and saves the time of modeling the irregular shapes of the defects.
\end{abstract}

Keywords: 3D range, Camera, Laser Scanner, Defect, Transform, Model.

\section{Introduction}

The applicability of the dimensional and defect quality inspection system is currently limited only to building elements with a rectangular-shape and a uniform thickness, and further investigation is warranted to extend to other types of building elements and defects that have more complex geometries (e.g. some building, columns and bridge biers and supports).

* Assistant Lecturer and PhD Candidate, Civil Engineering Dept., Faculty of Engineering, South Valley Univ., Qena, Egypt, PhD Researcher Visitor in Concordia Univ., Montréal, Québec, Canada/Email: DrMohamed.Saleh@Eng.svu.edu.eg.

$\dagger$ Professor, Concordia Institute for Information Systems Engineering, Concordia Univ., Montréal, Québec, Canada/Email: Hammad@ ciise.concordia.ca.

$\$$ Professor, Civil Engineering Dept., Faculty of Engineering, Al Azhar University, Cairo, Egypt/Email: nokrashy@yahoo.com.

$\S$ Assistant Professor, Civil Engineering Dept., Faculty of Engineering, Assiut Univ., Assiut, Egypt/Email: a.abdelhafiz@yahoo.com.

"Assistant Professor, Civil Engineering Dept., Faculty of Engineering, South Valley Univ., Qena, Egypt/Email: farag40@yahoo.com. 
Engineering structures (such as bridges, buildings, roads, water pipe lines, etc.) are subjected to defects, deformations and failures due to natural factors such as natural freezing and thawing cycles, problematic soil, changes of ground water level, etc. Therefore, there are many severe consequences that could result from the failure of a large structure. In addition to jeopardizing public health and safety, environmental contamination and significant economic loss are also of major concern.

For these reasons, early detection of possible structural damage is critical. This stimulates the need for a reliable methodology for routine structural defect monitoring. Monitoring and analyzing deformations of these structures constitutes a special branch of Geodesy. There are several techniques for measuring the defects and deformations. These can be grouped mainly into two as geodetic and non-geodetic techniques $[1,2]$.

One objective of this research is advance the use of range sensors, such as (IR camera and Laser Scanner) to monitor for defects and errors of the building elements, in previous case studies, the researchers used laser scanners to scan building sites periodically and created "as-built" models of each site, and geometric discrepancies were detected as defects, So the main objectives of this paper are:

1- Enhancement the building defects inspection by simplification the method of information visualization and adding inspection observations to the BIM, with comparison between the "as-built" models from 3D range sensors and the "designed models" to detect the geometric discrepancies and defects.

2- Investigate the limits of detecting defects in building models and predict the possible extension and the development of these defects and their effects, based on 3D data of light reflective objects using (IR camera and Laser Scanner) with different accuracies.

Recently 3D Range Sensor (Laser Scanner and IR Camera) are important techniques for measuring the defects. Existing techniques of surveying by 3D Range Sensor used to monitor large structures such as bridges and buildings, while very accurate, are greatly hindered by their low point density, range and accepted resolution in case of IR camera, but with work in short time and low cost.

Surface crack defect identification and maximum crack width determination have long played important roles for condition and risk assessment of buildings [3, 4], [5, 6] mentioned that several instruments have been developed to either detect visible cracks defect or measure crack characteristics (e.g. length and width). Mechanical probes and electronic sensors are generally used. [7] presented the fundamental mathematics to determine the minimum crack defect width detectable with a terrestrial laser scanner in unit-based masonry. Orthogonal offset, interval scan angle, crack orientation, and crack depth are the main parameters.

While image-based methods can provide good accuracy, they require supplementary information that is not always readily available, such as camera lens, focal length, or the exact distance from the camera to the target surface. As an alternative, interest in terrestrial laser scanning has rapidly increased. However, to date, most research using laser scanners in structural assessment has focused on measuring structural deformation, estimating material loss, or finding surface defects [7].

Registration the geometry with the digital image has created a new technique of data presenting, which can be used in structural engineering to complete drawings for an as-built 
structure or to test the actual dimensions of the as-built structure against its design. The dramatic decrease in the cost of computers coupled with the high increase of the Internet bandwidth is making the use of complex 3D digital models accessible to a much larger audience [8].

Limitations of 3D scanning include the time required to perform a single scan (when using high angular resolution) and the number of scan-positions necessary to acquire accurate information. Every pulse will produce a pixel or a point in a point cloud that represent a range image. The limitations of applying LADAR are the long time required to do each scan and the high cost associated with the equipment. The best results are obtained when many scans are taken from different locations to increase resolution and avoid physical obstructions that may lie between the scanner and the object [9].

In the following, it can be found short descriptions of the common defects types and some used techniques in its measurements.

\section{Common Defects Types}

\section{Defects in Concrete Bridges}

Common defects of concrete structures are numerated as different types of cracks, scaling, and collision damage, etc. Fig.1. Crack width can be measured by a crack comparator. [10] proposed image-based retrieval of crack properties in concrete components which uses image processing techniques to extract the properties of the superficial and visual cracks; however, their method involves only crack as target and it requires a clean component surface for crack detection.

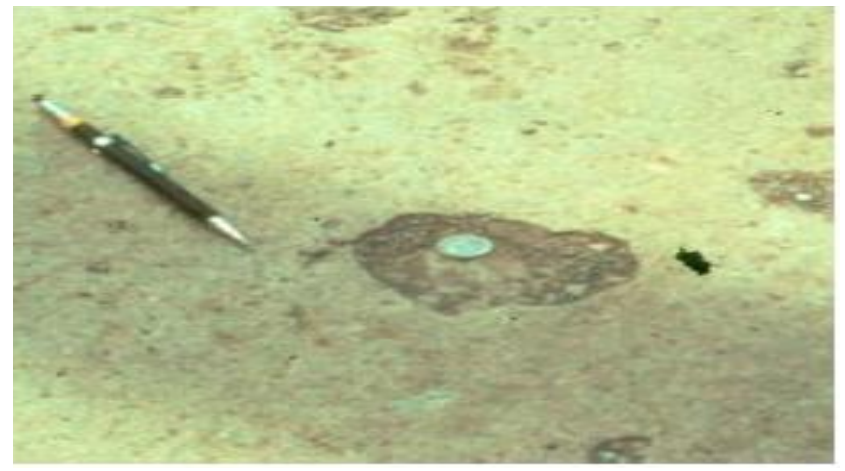

Fig.1. Scaling defect on concrete structure deck

For example in Montreal, Turcot interchange and the Champlain Bridge are deformed by cracks; there are many possible reasons to form these defects, when moisture gets into concrete, natural freezing and thawing cycles can cause it to crack in Fig. 2. in the case study.

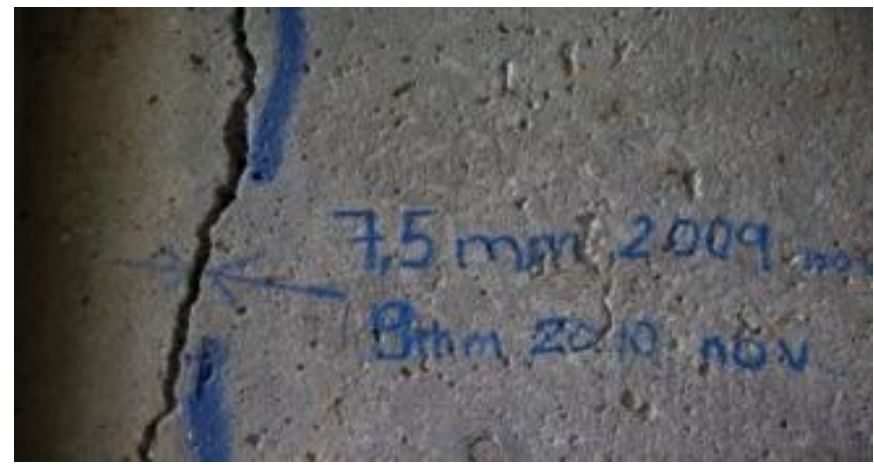

Fig.2. Crack in concrete in Turcot interchange [11]. 


\section{Defects in Buildings}

Common defects of building structures are shown in [12] and in the next Figs. 3-a, b, and $\mathbf{c}$ as different types of defects, spalling damages and cracks in load-bearing interior walls built of sandstones, cracks dimensions can be measured by the crack measuring tapes in the building [13].
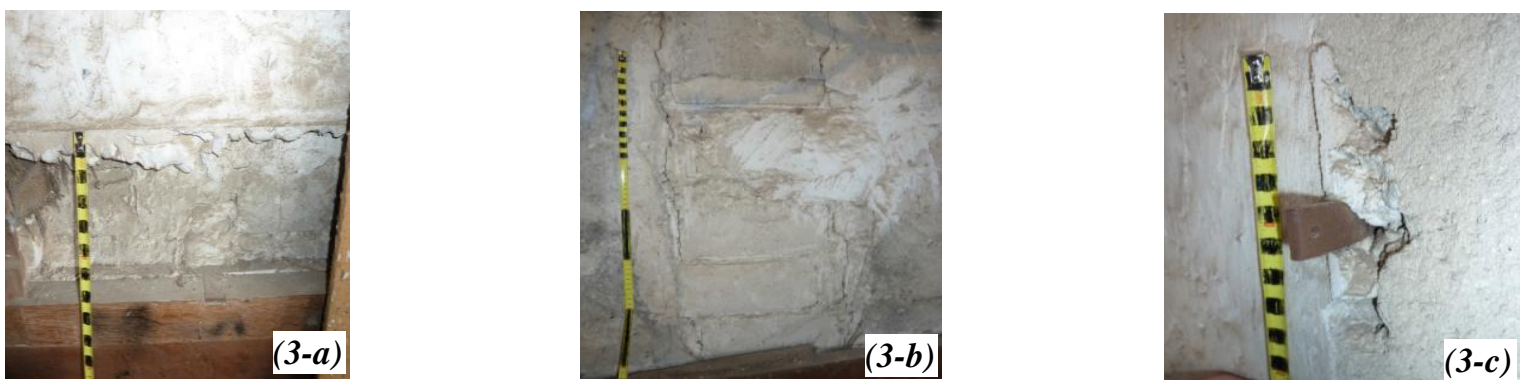

Fig. 3-a. Spalling in horizontal block. 3-b. Cracks in brick format. 3-c. Attachment wood panel and Spalling in the wall

\section{2- Producing Digital 4D defects Information Models (4DDIM)}

Four dimensional defects information models of building objects are rapidly becoming more affordable in many fields such as defect inspection, time visualization, animation and identification. Photo realistic models of the defects are also needed for the defect digital archiving. These models are beneficial in case of loss or damage. In this paper, the methodology of producing 4D defects information models consists of several steps (Fig.4) which are:

1- Defect capturing, translation and points recovering,

2- Defect modeling and surface reconstruction, 3- Defect texture mapping, 4- Defect time visualization.

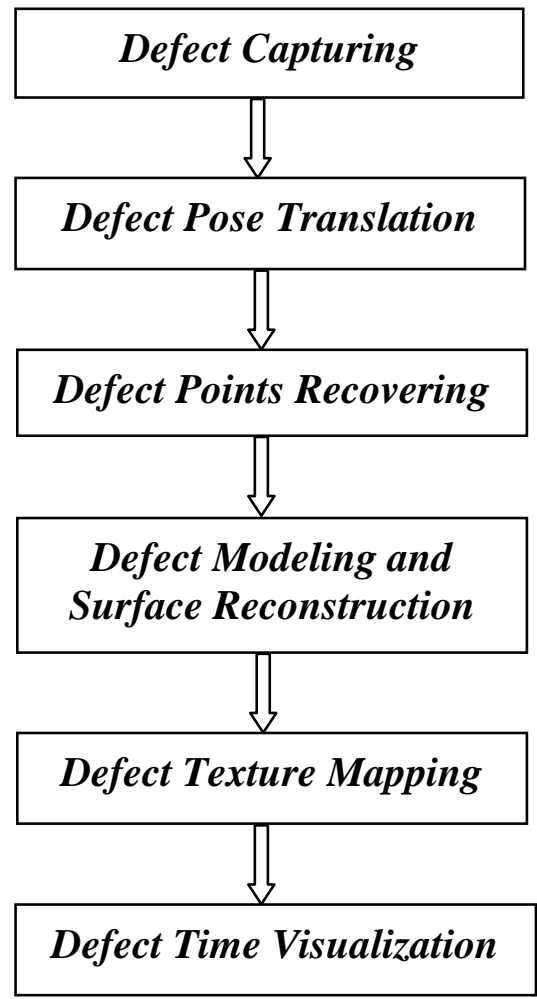

Fig.4.The methodology of Producing Digital 4D Defects Information Models (4DDIM) 
Details of the full pipelines for digital 4D defects information models (4DDIM) generation and the pre-mentioned steps are given in the next sub sections.

\section{2-1 Defect capturing, translation and points recovering}

Two techniques can be commonly employed in order to recover concerning object defects. These two techniques are the passive photograph based technique and the active range based technique. The suitable technique is selected by considering the application type, the geometric accuracy, realism, and the cost.

\section{2-1-1 Passive Photograph-based technique}

In the passive photograph based technique; one can consider the following three main steps in order to recover a certain object defect:

1) Defects photographing, 2) Determining interior and exterior sensor orientations for the captured defect images, 3) Measuring defects feature points in the images and consequently computing space coordinates for the measured defects points.

The three steps will be described in the following sub sections.

\section{2-1-1-1 Defects Photographing}

In case of two images, is required to recover the defect by photogrammetry. The positions of the captured images have to be distributed around the concerning object defects horizontally and vertically in order to have clear rays intersection and consequently accurate space coordinates, refer to $[14,8]$.

\section{2-1-1-2 Sensor orientations}

After capturing the defect images, their parameters are defined by determining the interior and the exterior orientations.

\section{Interior orientations}

Interior orientations represent the position of the perspective center with respect to the image coordinate system $\left(\boldsymbol{x}_{p}, \boldsymbol{y}_{p}\right.$, and $\left.\boldsymbol{f}\right)$. Lens distortion forms are also a part of the elements of interior orientations. These values are normally determined by the means of camera calibration. The camera can be calibrated under control in the laboratory, or calibrated using the same project images (self-calibration) [15].

\section{Exterior orientations}

The position and orientations of the photograph of the defect in the object space are defined by its exterior orientations. The position of a photograph is defined by the object coordinates of the perspective center. While the photograph angular orientations are defined by the rotations around the three axes. Collinearity, Coplanarity, and Direct linear transformation method can be used in principle to determine the absolute exterior orientations of the camera employing a number of control points (natural/artificial) [16]. 


\section{2-1-1-3 Computing space coordinates for the measured defect points (Defect Points recovering)}

Corresponding image defects points can be measured after having oriented images with manual, semi-automatic, or automatic procedures. Then a forward intersection using Collinearity equations is applied to recover the space coordinates [8]. After measuring conjugate defects points in the images, the matched 2D coordinates are transformed to 3D object coordinates using the recovered interior and exterior orientations (forward intersection). Defect modeling, texture mapping, and $4 D$ visualization can be then applied as will be described later in this methodology.

\section{2-1-2 Active Range-based technique}

Active range-based technique is based mainly on using the Laser or IR rays in measuring distances. The technology of laser scanning and IR capturing, are discussed in the following sub sections.

\section{2-1-2-1 Laser scanning}

Laser scanners measure the distance from the sensor to nearby surfaces with millimeter to centimeter accuracy at speeds of thousands to hundreds of thousands of point measurements per second as Fig. 5. So, the space coordinates relative to the scanner pose can be easily computed. Often, a digital camera is used to capture images of the environment, which can be later fused with the 3D data to aid in the modeling process [17].

The laser scanner measures also an intensity value for each point in the defect position. The intensity is defined as a measure of the electronic signal strength obtained by converting and amplifying the backscattered optical power [8].

a

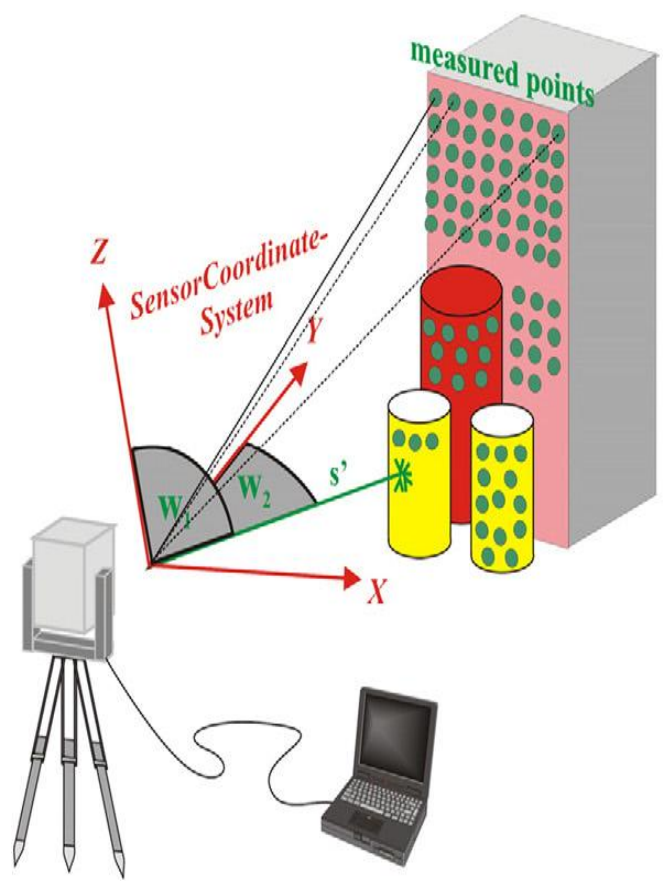

b

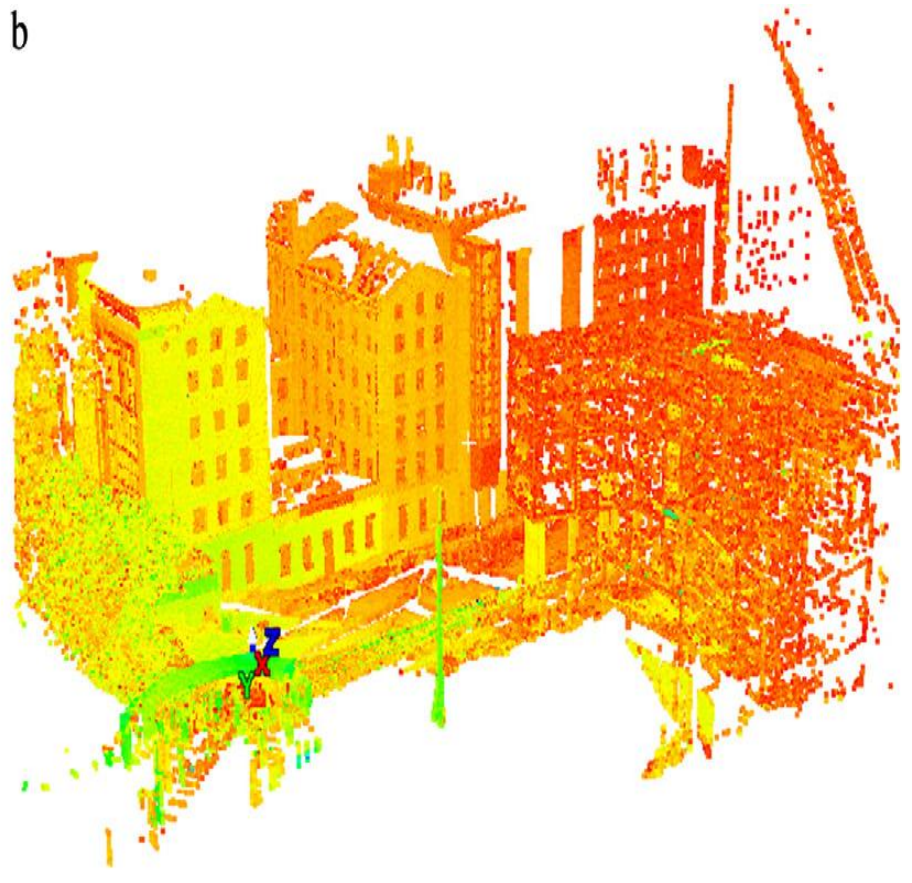

Fig.5 (a) the laser scanning process for measuring 3D points (from [18] reproduced with permission of R. Staiger). (b) An example of laser-scanned data of a building under construction [19]. 


\section{2-1-2-2 Scanning methods}

Laser scanners are active sensors which use mainly three methods of scanning. These methods are the time of flight (e.g. Leica and Trimble), the phase difference (e.g. Faro and $\mathrm{Z}+\mathrm{F})$, and the triangulation. In the time of flight method, the time required for the laser signal to travel from the source transmitter to the target and return back to the detector is measured accurately by a nanosecond stopwatch. By knowing the exact value of the light speed, the distance between the laser scanner and the target can be computed.

\section{2-1-2-3 IR Range Camera}

The IR Range Camera in Fig. 6 has the distance measurement capability based on the Time of Flight $(T O F)$ principle, like as stated before in case of the laser light for a description of this principle. Again in Time of Flight systems, the time taken for light to travel from an active illumination source to IR light reflective objects in the field of view and back to the sensor is measured. Given the speed of light c, the distance can be determined directly from this round trip time. The distance at each pixel is determined as a fraction of the one full cycle of the modulated signal, where the distance corresponding to one full cycle is given by:

$$
D=c / 2 f
$$

Where $\mathrm{c}$ is the speed of light and $\mathrm{f}$ is the modulation frequency. At a modulation frequency of $30 \mathrm{MHz}$, this distance is $4.997 \mathrm{~m}$ at a speed of light $299792458 \mathrm{~m} / \mathrm{s}$. Therefore, $30 \mathrm{MHz}$ cameras are those with the $5 \mathrm{~m}$ range in the product specifications and $15 \mathrm{MHz}$ cameras are those with the $10 \mathrm{~m}$ range.

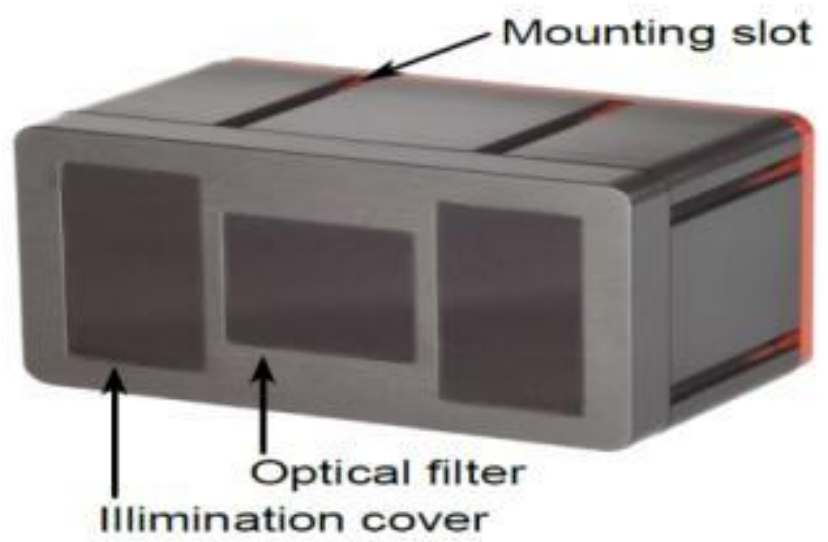

Fig. 6: The Front view of IR Range Camera SR4500 [20]

\section{2-1-2-4 Distance estimation and 3D measurements}

One burst of the modulated signal is sent out for each image and multiple phase shifts are integrated during this time. The lengths of the integration process can be adjusted by the user by means of a parameter called Integration Time (IT).

The real spherical distance in mm can be obtained by multiplying the 14-bit phase measure with the factor of $0.305 \mathrm{~mm}$ or $0.61 \mathrm{~mm}$ respectively. From this distance together with the intrinsic parameters of the camera $x, y$ and $z$ coordinates per pixel are computed. This is done inside the camera so that it delivers full 3D coordinate vectors for each of the 176 times 144 pixels [20]. 


\section{2-1-2-5 Calibration Test}

A Calibration approach is used to characterize the precision of the camera. For an object (Checkerboard) as shown in Fig (7a), at a given (known) distance $=3.375 \mathrm{~m}$ measured by measuring tape and digital distance measurer shown in Fig. (7b), (7c), repeating the distance measurement with the camera will result in a distribution of measured values of $3.385,3.395,3.377,3.405$... centered on a mean value.

(a)

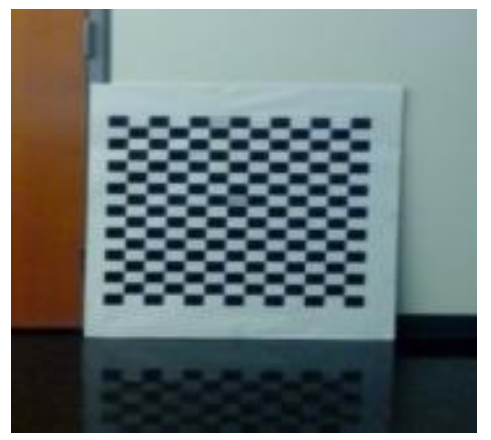

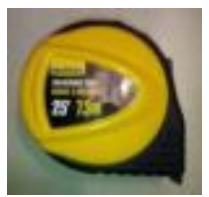

(b) (c)

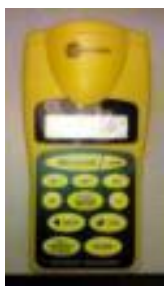

Fig.7. (a) Checkerboard for the test, (b) measuring tape, (c) digital distance measurer

In Fig.8, 3D view of the checkerboard is seen behind the display cross center, and the measured distance $=337.7 \mathrm{~cm}$, appears in the left upper corner of the main screen, and the checkerboard is seen also in the intensity image in the left middle window, and XYZ Cartesian coordinates data output as ASC file are shown in Fig. 9.

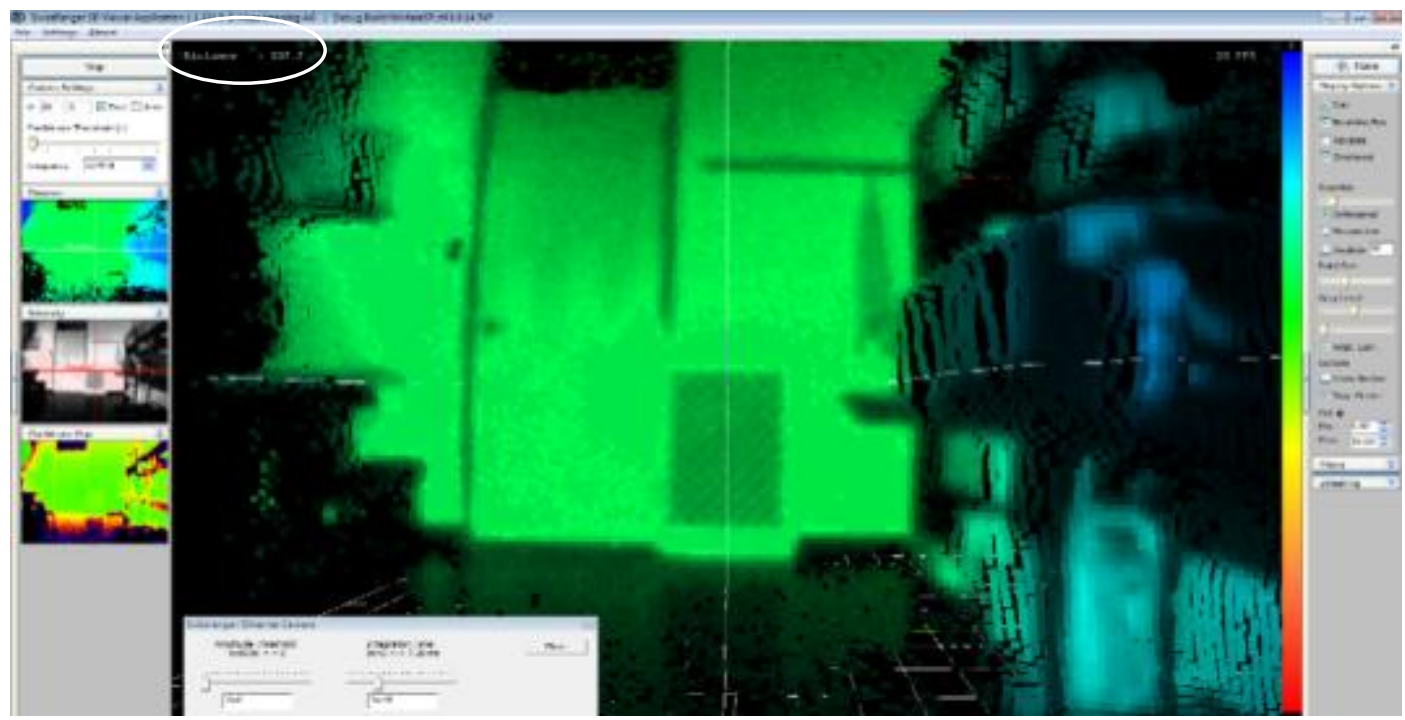

Fig.8. 3D view of the checkerboard is seen behind the display cross center, and the measured distance

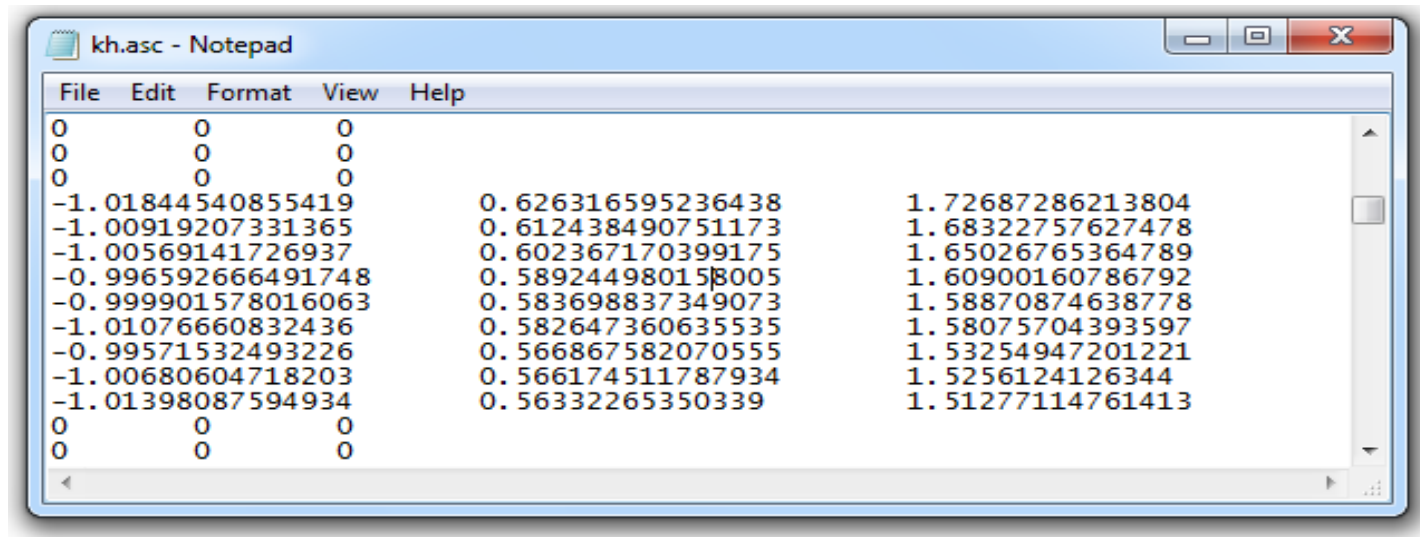




\section{2-1-2-6 XYZ Cartesian coordinates of the camera}

The software driver of the IR Range Camera provides a coordinate transform function. This transformation includes a correction which compensate for the radial distortion of the optics. The coordinate system used here is "Right-Handed", with z-coordinate increasing along the optical axis away from the camera, $y$-coordinate increasing vertically upwards and $\boldsymbol{x}$-coordinate increasing horizontally to the left, all from the point of view of the camera (or someone standing behind it), as shown in Fig.(10) the camera's output coordinate system. The origin of the coordinate system $(\mathbf{0 , 0 , 0 )}$ is at the intersection of the optical axis with the front face of the camera.

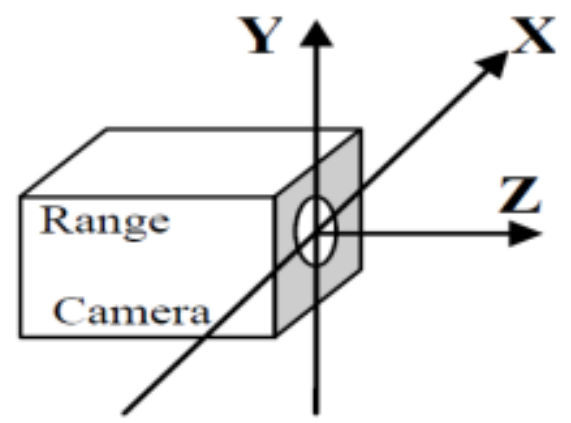

Fig.10. The camera's output coordinate system

\section{2-2 Defect capturing and translation in range based technique}

The coordinates of the defect pose at point $P_{1}$ with respect to object plane will be transformed into a new coordinate system with respect to station $L$ of the $3 D$ range sensor (IR camera or laser scanner). Fig. 11 shows the geometry of the photograph of the object defect plane, the sensor station $L$ is at distance $h$ from the defect plane $(0.8-9 \boldsymbol{m}$ in case of $I R$ camera), the principal axis $L P_{o}$ is perpendicular to the plane and intersecting its surface at point $P_{o}$ "principal point" In the following, General formulas for the photos have been established which will be used to recover the coordinates for different defect points as $P_{1}$ on the object plane, and inverse formulas of coordinates transformation are included in the following subsections.

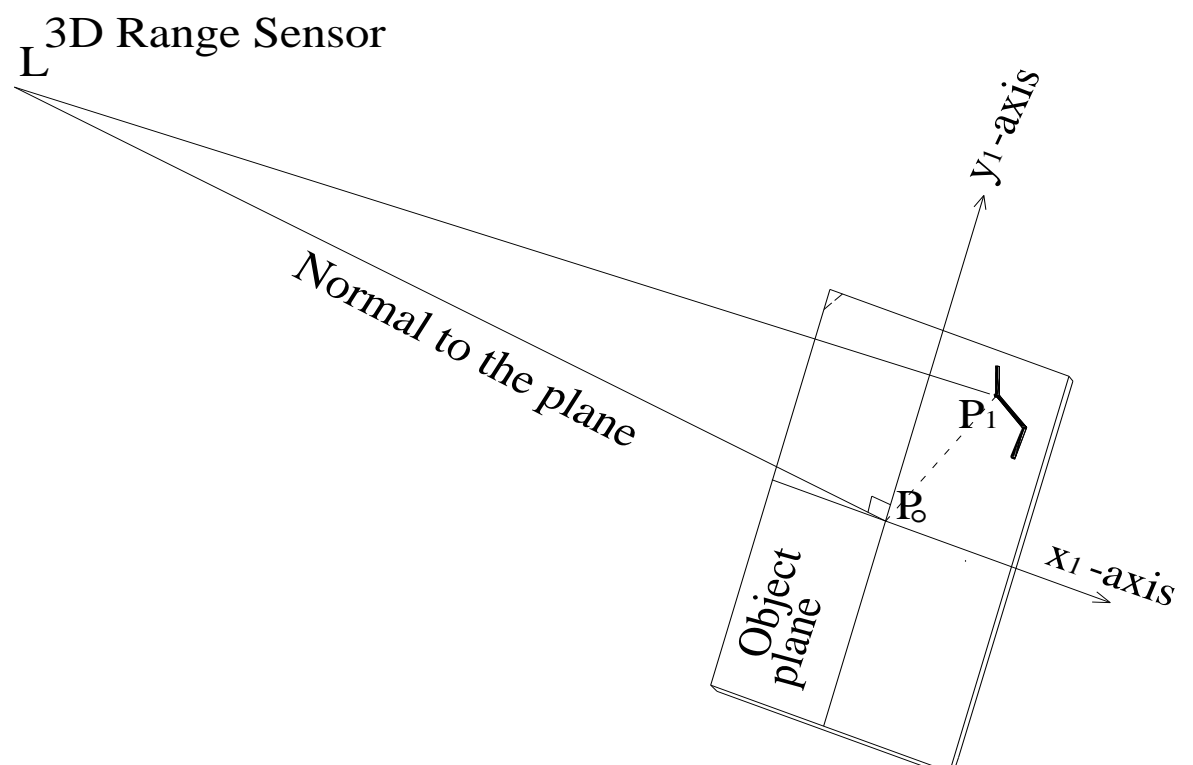

Fig. 11. Detection and Capture of the object defect $\mathrm{P}_{1}$ 


\section{2-2-1 The coordinates onto the defect plane}

In the object defect plane, let the assumed system of Cartesian coordinates $\left(x_{1}, y_{1}\right)$ be such that the $y_{1}$-axis increasing vertically upwards through $P_{o}$, while the $x_{1}$-axis is perpendicular to the $y_{1}$-axis, increasing horizontally to the right [21]. Fig.12 shows the system of rectangular coordinates of the object defect plane.

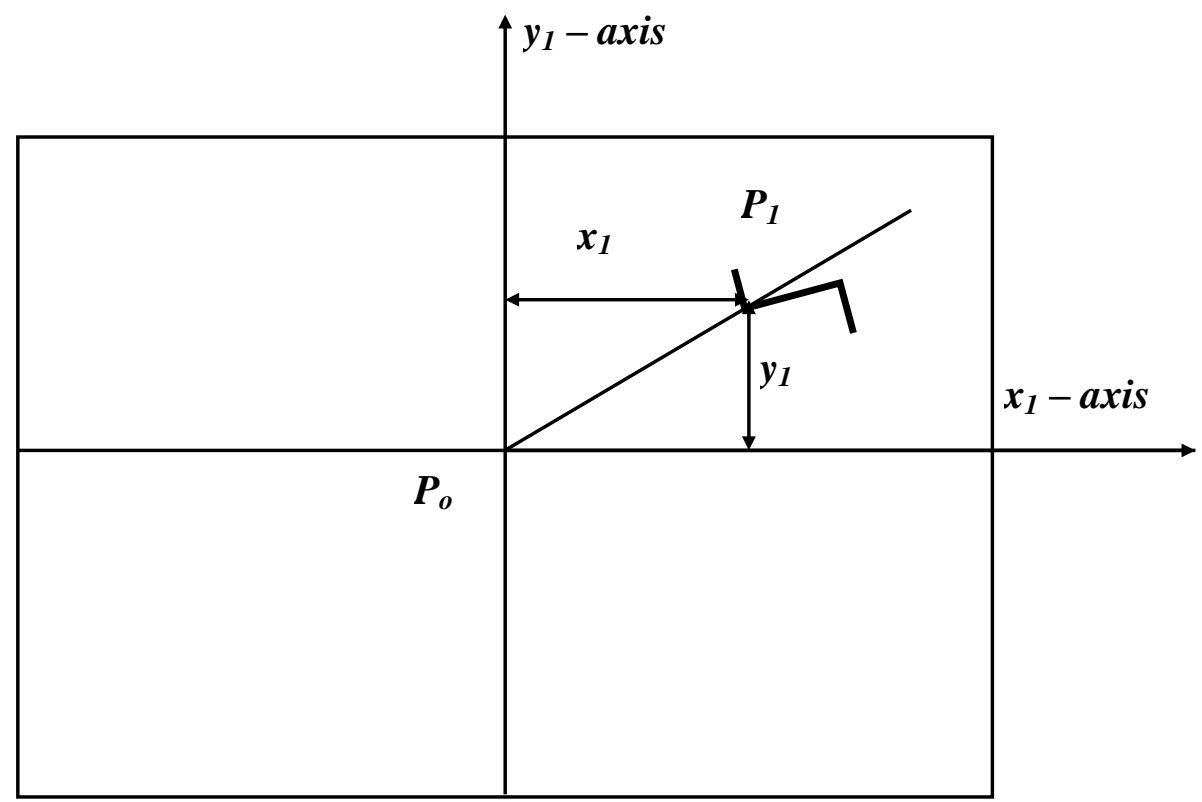

Fig.12. System of Cartesian coordinates of the object defect plane.

2-2-2 Rotation of the coordinate axes of the defect plane

In the object defect plane is considered that the $y_{1}$-axis is due upwards, this is not always the general case, so the coordinate axes $\left(x_{1}, y_{1}\right)$ of the object defect plane will be rotated to the axes $\left(x_{2}, y_{2}\right)$, the $y_{2}$-axis makes clockwise angle $\gamma$ with the $y_{1}$-axis, the new coordinates $x_{2}$ and $y_{2}$ of $P_{1}$ are:

$$
x_{2}=x_{1} \cos \gamma-y_{1} \sin \gamma
$$

$$
y_{2}=x_{1} \sin \gamma+y_{1} \cos \gamma
$$

\section{2-2-3 Capture and translation onto the virtual tilted plane as the general case}

Let $P_{1}$ be photographed through $L$ onto a virtual tilted plane through $x_{2}$-axis. As shown in Fig. 13. The tilted plane makes an angle $t$ with the defect plane. The coordinates $(x 3, y 3)$ of the point P2 in the virtual tilted plane, with the origin of axes at Po are to be found. Let the $\mathrm{x} 3$-axis lie at the intersection of the two planes (the defect plane and the virtual tilted plane) (i.e. $x 3=x 2$ ), then the $y 3$-axis lies in the principal plane LPoy2. The rectangular coordinates $(\mathrm{x} 3, \mathrm{y} 3)$ of $\mathrm{P} 2$ on the virtual tilted plane depend on the coordinates $(\mathrm{x} 2, \mathrm{y} 2)$. From the triangle $P_{1} P_{2} P_{o}$, we get: 


$$
\begin{aligned}
& y_{3}=h y_{2} /\left(h \cos t+y_{2} \sin t\right) \\
& x_{3}=h \cos t x_{2} /\left(h \cos t+y_{2} \sin t\right)
\end{aligned}
$$

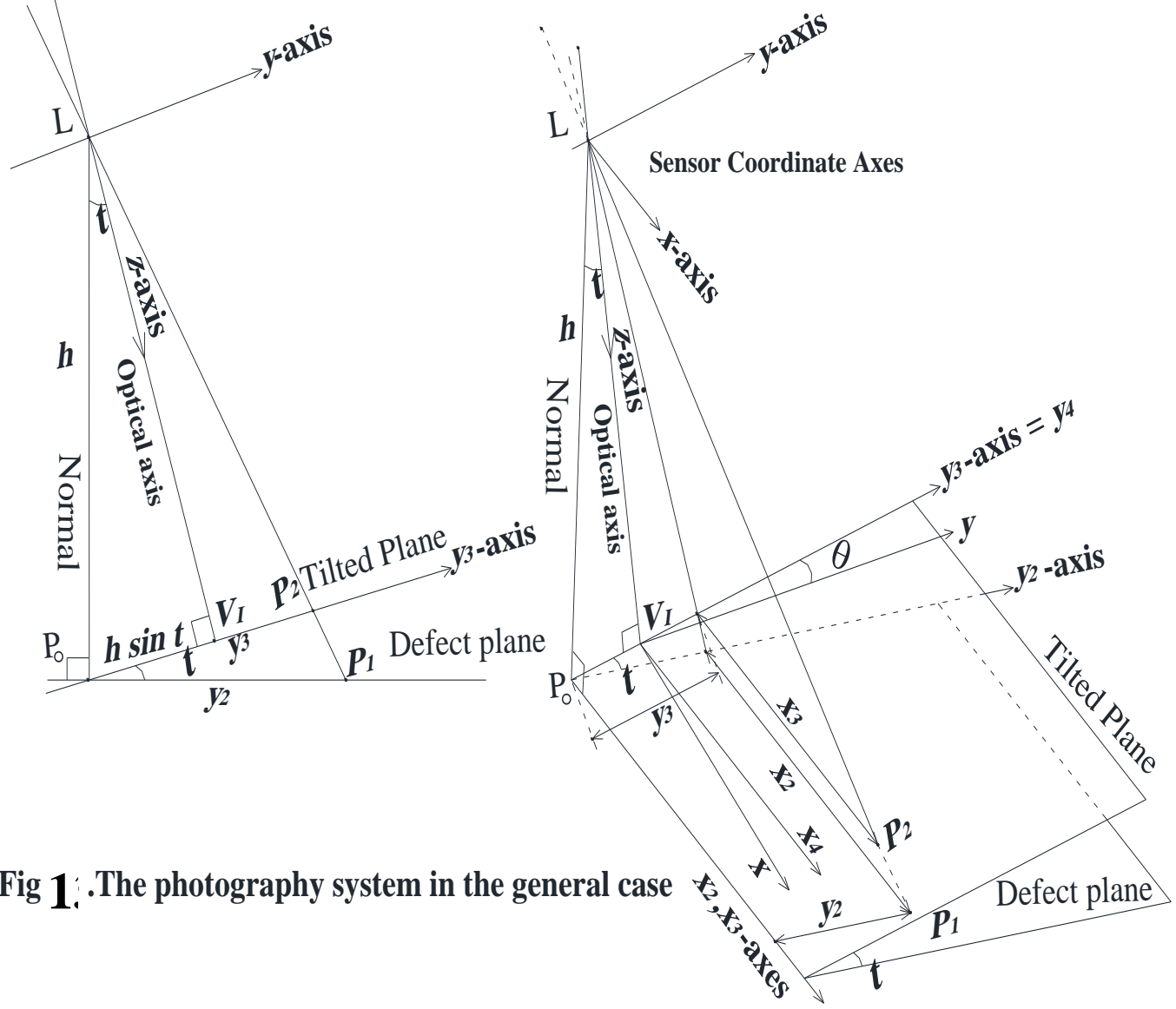

\section{2-2-4 Translation and rotation of the axes onto the virtual tilted plane}

On the inclined photographs, $P_{o}$ can't be precisely located, while center $V_{I}$ along the optical axis can be located if the picture has been adjusted for this aim $[22,23]$. So the need arises to translate the origin of the axes from $P_{o}$ to $V_{I}$ along the ordinate axis $P_{o} y_{3}$, as shown in Fig. 13.

Consequently, all ordinates from equation (4) become shorter by distance $\left(P_{o} V_{I}=h \sin \right.$ $t$ ), while the abscissas remain unchanged. The point $P_{2}$ has now the translated coordinates $x_{4}$ $\& y_{4}$ as follows:

$$
\begin{aligned}
& x_{4}=x_{3} \\
& y_{4}=y_{3}-h \sin t
\end{aligned}
$$

If the $x_{4}, y_{4}$ coordinates are rotated by an angle $\theta$ around $V_{I}$ in the virtual tilted plane as a general case, and if the $x$ and $y$ are the new axes, as shown in Fig. 13, then the rectangular coordinates of $P_{2}$ related to this system, become:

$$
\begin{aligned}
& x=x_{4} \cos \theta-y_{4} \sin \theta \\
& y=x_{4} \sin \theta+y_{4} \cos \theta
\end{aligned}
$$




\section{2-2-5 The Final defect coordinates on the range sensor image}

In the range sensor image taken from the exposure station $L$, the $y$-axis of the sensor is taken through $L$ parallel to the $y$-axis in the virtual tilted plane, and the $x$-axis of the sensor is perpendicular to $y$-axis and parallel to the $x$-axis in the virtual tilted plane, and the $z$-axis increasing along the optical axis away from the sensor, as shown in Fig. 13, the defect coordinates $(x, y$, and $z){ }_{\text {defect }}$ on the sensor image are determined as follows:

$$
\begin{aligned}
& x_{\text {defect }}=x \\
& y_{\text {defect }}=y \\
& z_{\text {defect }}=\text { distance along } z \text {-axis from L to the tilted plan }
\end{aligned}
$$

\section{2-2-6 The Inverse equations of the defect}

To calculate the coordinates $\left(x_{1}, y_{1}\right)$ of the defect plane in terms of the coordinates $(x$, $y)_{\text {defect }}$ on the sensor image, substituting from equations (2) through (11), we obtain:

$$
\begin{aligned}
& x_{1}=h \frac{D_{1} y+D_{2} x+D_{3}}{h \cos ^{2} t+(x \sin \theta-y \cos \theta) \sin t} \\
& y_{1}=h \frac{D_{4} y+D_{5} x+D_{3}}{h \cos ^{2} t+(x \sin \theta-y \cos \theta) \sin t}
\end{aligned}
$$

Where,

$$
\begin{aligned}
& D_{1}=\sin \gamma \cos t \cos \theta+\cos \gamma \sin \theta \\
& D_{2}=\cos \gamma \cos \theta-\sin \gamma \cos t \sin \theta \\
& D_{3}=h \sin \gamma \cos t \sin t \\
& D_{4}=\cos \gamma \cos t \cos \theta-\sin \gamma \sin \theta \\
& D_{5}=-(\cos \gamma \cos t \sin \theta+\sin \gamma \cos \theta) \\
& D_{6}=h \cos \gamma \cos t \sin t
\end{aligned}
$$

\section{2-3 Object defect Recovery using range sensors}

IR capturing and laser scanning are the two techniques for objects defects recovery. Each technique has its own points of strength and weakness. According to the application, surveying by laser scanning used to monitor large structures such as bridges and buildings are very accurate. 


\section{2-4 Defect modeling and Surface reconstruction}

This steps focus on modeling 3D images Fig. 14 collected using LiDAR equipment. The results of test scans performed in the laboratory, as well as the application of the method on a building defect are presented to demonstrate the use and benefits of the proposed methodology. The proposed method is adding the 4D model of the building defects from inspection observations as information objects to the BIM.

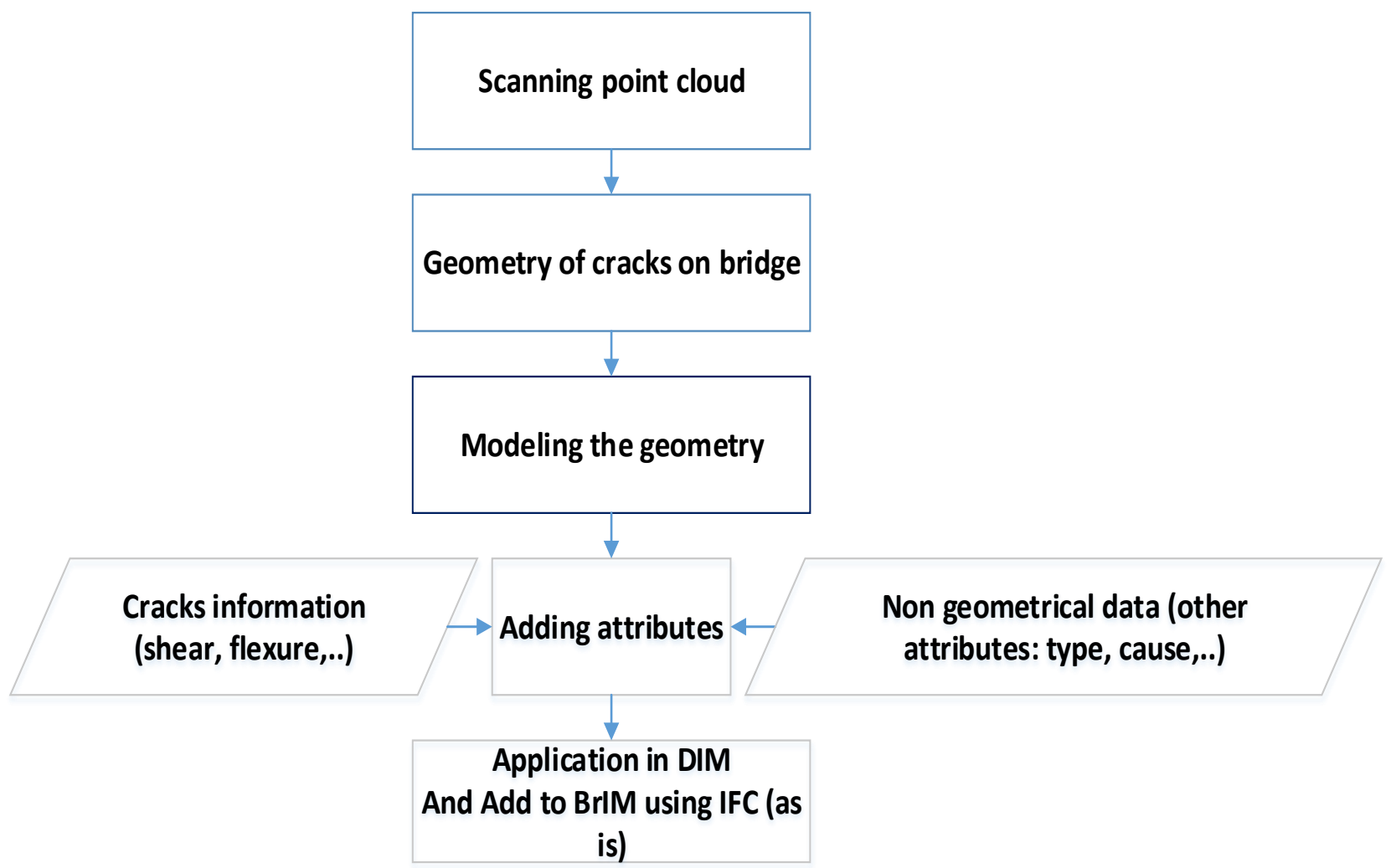

Fig.14. The method of modeling the defect (cracks) using Combination of BIM and 3D range sensors to create Defect Information Model (DIM) in the first case study.

\section{Wire frame}

For applications, like building defects reconstruction, the range based method is used to measure manually the defect critical points. These points are then connected together to create what is called the wire frame. For other applications (e.g. statues or complex objects) dense point clouds are required. Mesh generation from a point cloud is coming in two steps. The first is the meshing which requires certain techniques in order to automatically connect the points. The second is the manual editing made by a human operator to avoid errors caused by large gabs and/or noise [8].

\section{2-5 Defect texture mapping}

Wire frames and mesh models are the geometric representation for objects. The realism is added for those objects with the help of texture mapping technique using high resolution images. The geometry and the texture are then visualized in the virtual reality. Different techniques and methods have been developed to achieve more realistic texture mapping for 3D models [24, 25, 26, and 8]. 
In 3D Modeling, data is delivered in a variety of forms and formats; several 3D geometries are available including, polygon-mesh in Fig.15a, contours, and solid model in

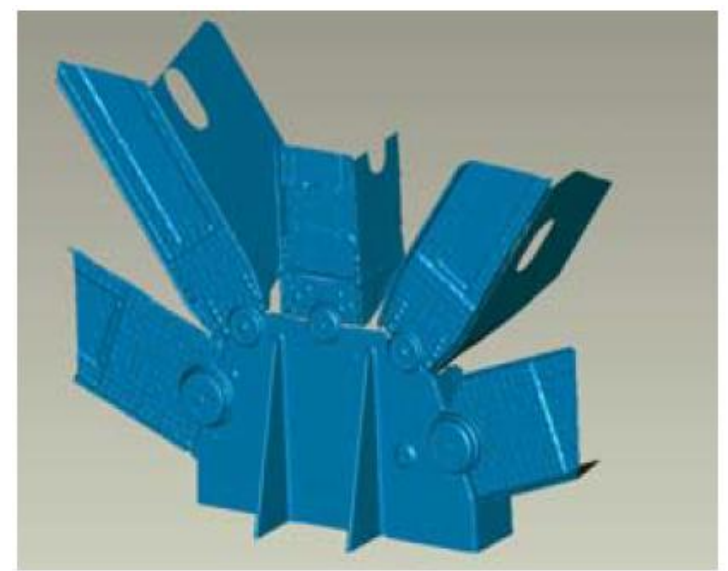

Fig. 15a: 3D polygon-mesh

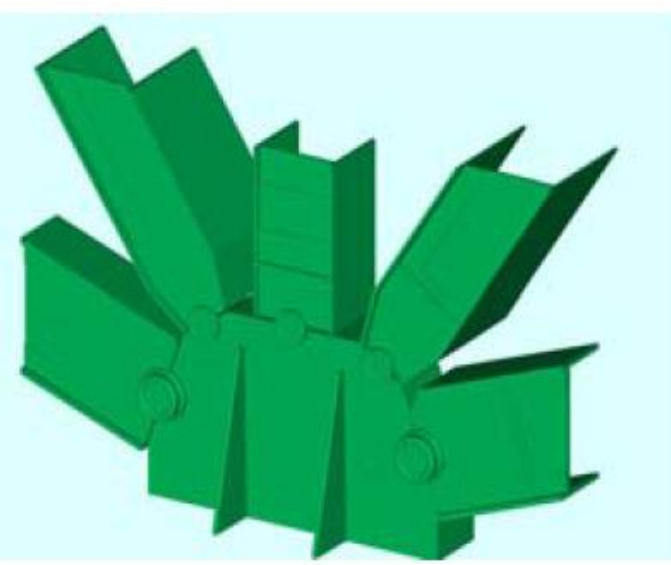

Fig. 15b: Solid model

Fig.15b. Commercial 3D modeling tools allow for both 3D surface/solid model creation and standard parts/steel profiles definition by using the best-fit techniques [27].

\section{2-6 Defect time visualization}

The time visualization process is concerned with presenting and handling 4D defects models (geometry and texture) on the computer screen using certain visualization engines (for instance interactive VRML engine). Computer game engines are also used to visualize 3D building models [28, 29]. The next mentioned techniques (Navigation, Picking Behaviors and LODs) are common techniques in computer graphics, applying these techniques in the proposed method.

\section{Graphical Navigation Mode}

The graphical navigation is achieved by interacting with the 4D model. Three navigation behaviors are investigated for the framework: drive, fly, and orbit behaviors. These behaviors use the pointing device (e.g., digital stylus or mouse) to control the view platform motion.

\section{Picking Behavior}

Interaction with the 4D model is mainly facilitated by picking the elements of the model. Picking is the process of selecting shapes in the 3D virtual world using the 2D coordinates of the picking device. In order to interactively retrieve or update information related to the picked element, it is important to know the location and the orientation of that element in the 3D environment of the virtual model.

\section{LODs}

The basic idea of LODs (Level of Details) is to use simpler versions of an object to meet different precision needs and improve the image rendering performance. LODs can be used in parallel with respect to different objects in the same system, such as the bridge element and the defects on the element. Each LODs group uses different referential center point and distance range and operates only on objects related to that group [30]. 


\section{2-7 The System Development}

To show the viability of the proposed methodology, a system is developed and discussed in this section. This system is planned to carry out the research requirements using the techniques discussed in previous sections to realize the following Case study purposes.

\section{3- The Case study}

[31] revealed the fact that $40 \%$ of in-service bridges in Canada are aged 50 or more. The importance of process improvement in Operation and Maintenance (O\&M) becomes of a significant importance $[32,33]$

Jacques Cartier Bridge is chosen as the subject of the case study. Jacques Cartier Bridge is a five-lane bridge with about $2.7 \mathrm{~km}$ in length, spanning the St. Lawrence River between the cities of Montreal and Longueuil [34]. The old reinforced concrete bridge deck had suffered seriously from the increase of the number and load of trucks and the de-icing salts used extensively since the 1960s. Consequently, the deck was replaced in 2001 and 2002. The new deck is constructed of precast, prestressed and post-tensioned panels made of high performance concrete which were prefabricated in a temporary plant installed near the south end of the bridge.

The bridge data were acquired from the bridge management authority (The Jacques Cartier and Champlain Bridges Incorporated) [34, 35]. The data include AutoCAD drawings, deck rehabilitation schedules and inspection and maintenance records. Fig. 16 shows part of the inspection data of a floor-beam including metal loss and perforation. Fig. 17 shows the main span painting history of the bridge until 2000. Further details about the system can be found elsewhere [36, 37].

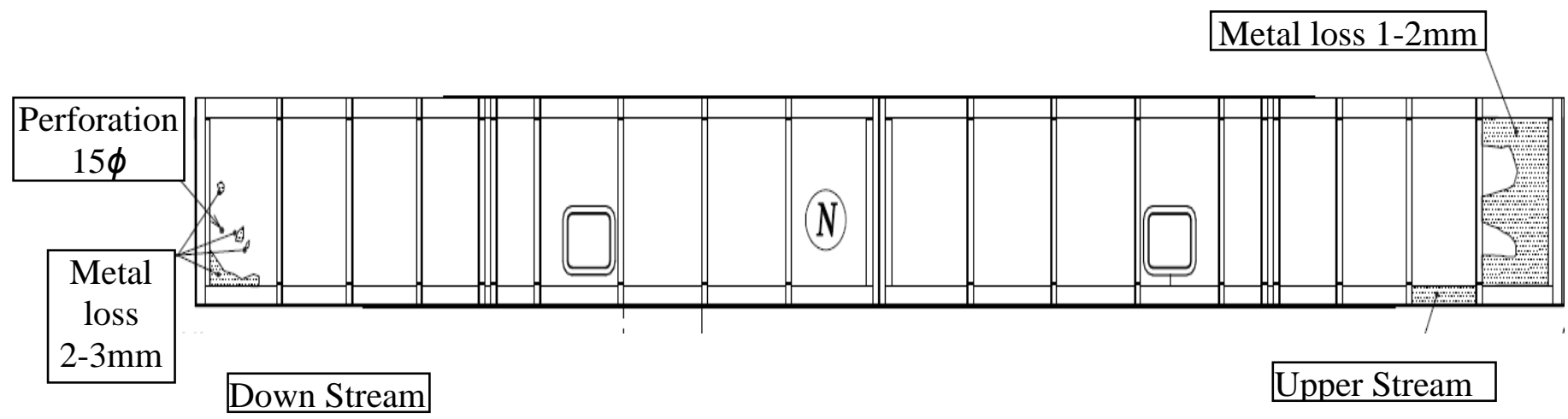

Fig.16 Example of floor-beam inspection information 

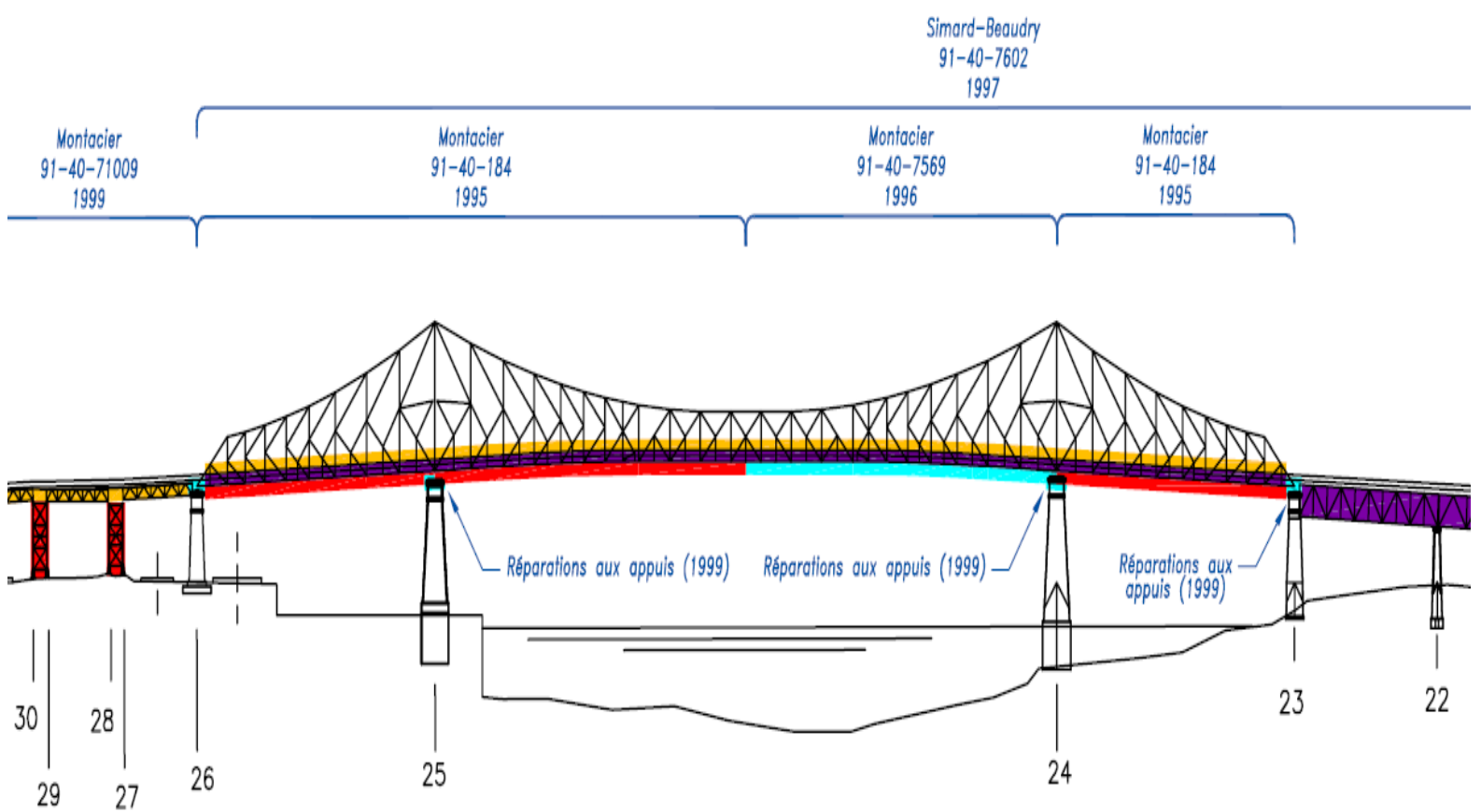

Fig.17 The main span painting history until 2000

One objective in this Case study is use of advanced range sensors such as (IR camera and Laser Scanner) to monitor defects and errors of the construction of a facility, in previous case studies, the researchers used laser scanners to scan construction sites periodically and created "as-built" models of each site in Fig. 18, these as-built models were then compared to the facility's “designed" model and geometric discrepancies were detected and flagged as potential defects.

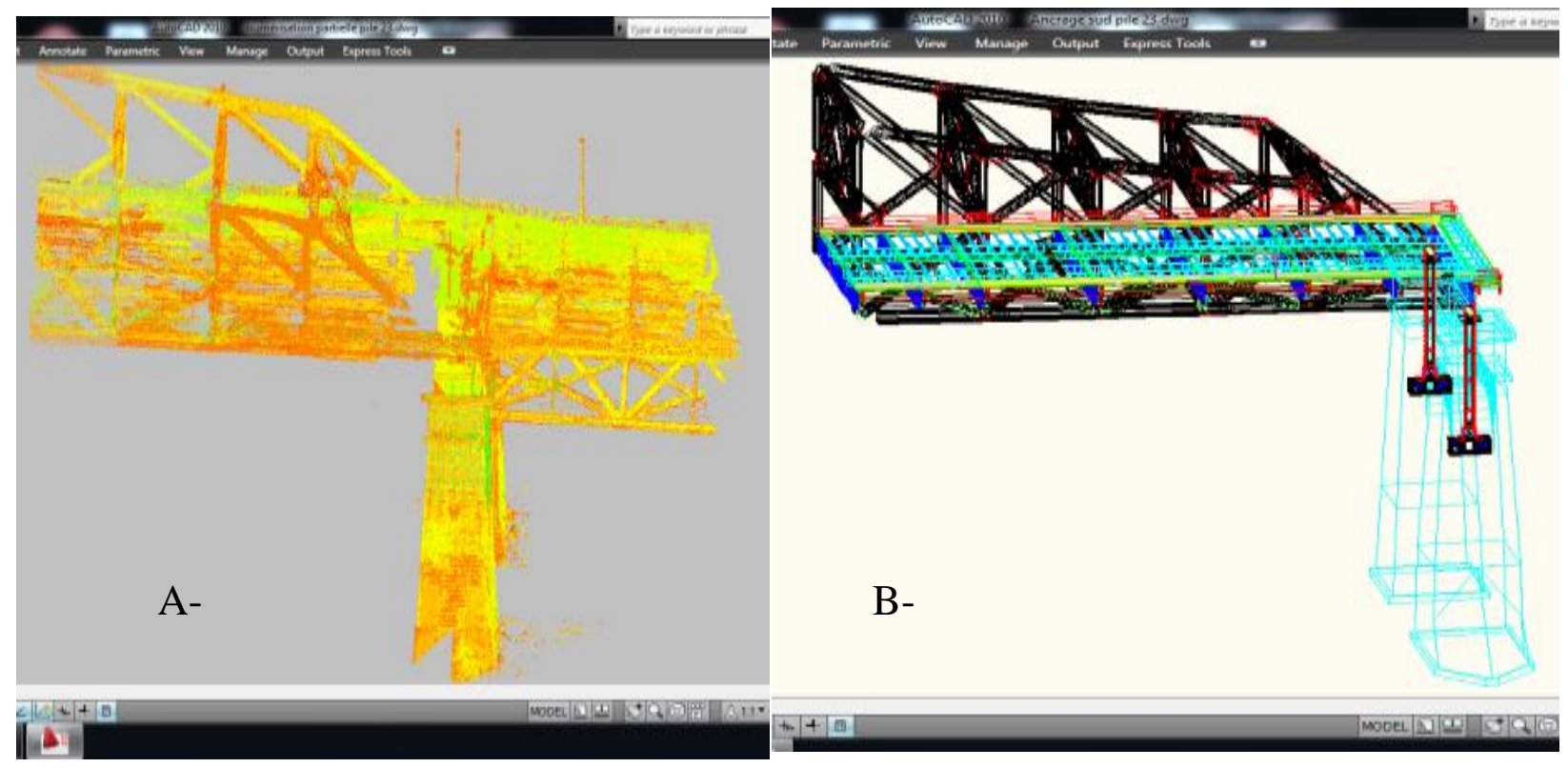

Fig.18. A- 3D Point cloud of pile 23 of the Jacques Cartier Bridge, B- CAD model of the pile 23

This research have been planned to symbolize the visual observation data in figure of digital forms (e.g., images and digital shapes) to the 3D model of the bridge. [36] proposed a location-based computing system to facilitate the data collection activities of the bridge 
inspection by registering defects on the 3D model of the bridge. [38] added of a predefined defect model from Inspection observations to the BrIM (Bridge Information Model) by direct interaction of the inspector with the model at the inspection site. However, their defect models aren't in its real shape.

This study proposes enhancement the building defects inspection by simplification the method of information visualization and adding 3D LIDAR (Laser or Range camera) structural defects observations to the BrIM. Standing on the method, the Defect Information Model (DIM) is in its real shape, which decreases the difficulty and saves the time of modeling the irregular shapes of the defects.

The proposed method with some results for capturing and modeling structural defects using $\boldsymbol{B I M}, \boldsymbol{D I M}$ and $\boldsymbol{L I D A R}$ are listed in the next steps.

\section{The steps in this proposed methodology are:}

1- The 3D bridge model as-built from the sensors (IR camera or Scanner) and the 3D bridge model as-designed from the $\boldsymbol{C A D}$ are opened on the observer's handheld device, and compared between them to detect the geometric discrepancies and defects limits, as Fig.19 shows the 3D designed model in $\boldsymbol{C A D}$ software in the right and 3D Laser model in RiSCAN modeling software in the left.

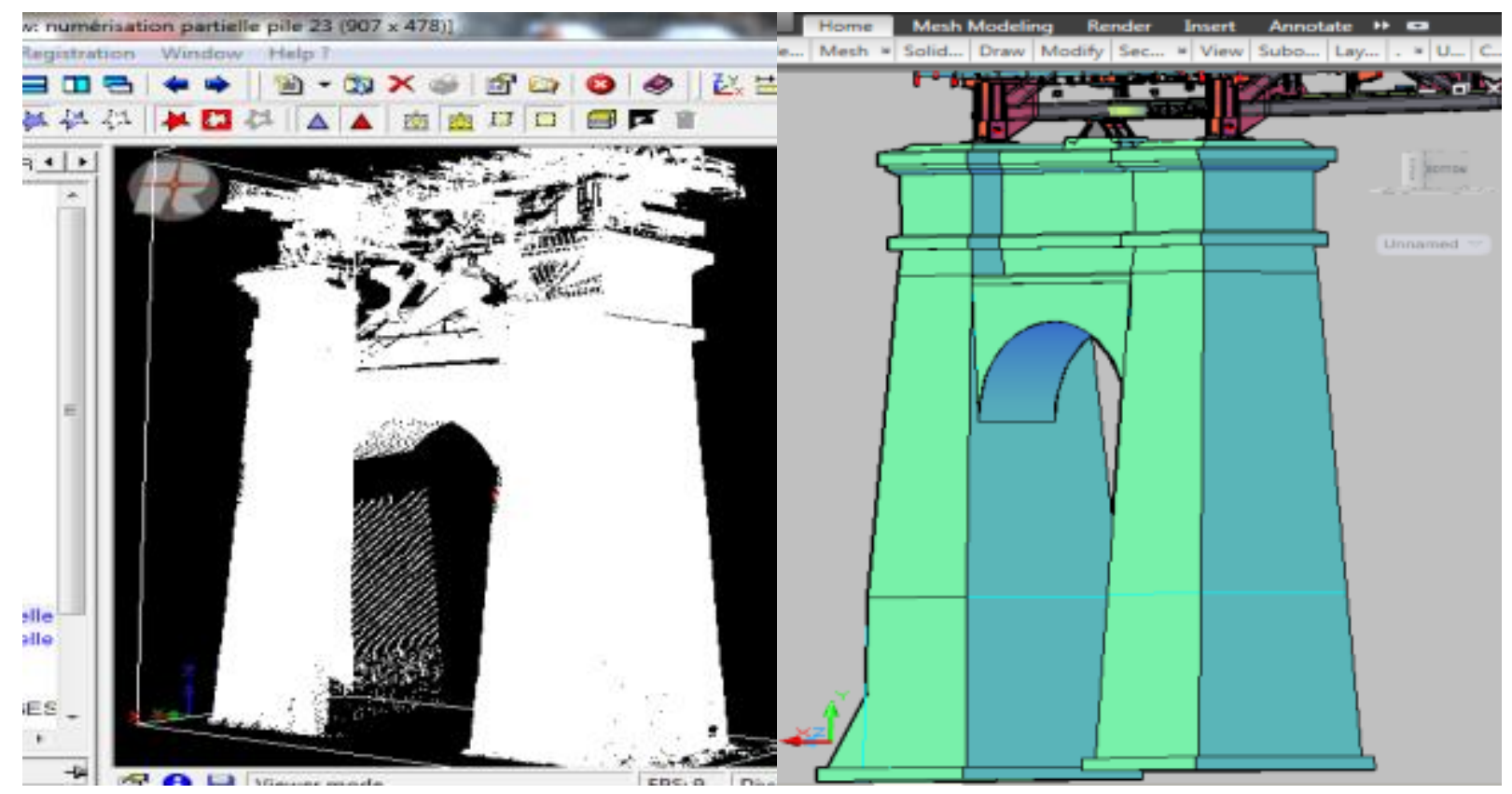

Fig.19. The 3D designed model in $C A D$ software in the right, and 3D Laser model in RiSCAN modeling software in the left.

2- List data of the inspection reports are reviewed to evaluate it, as Fig.20. 


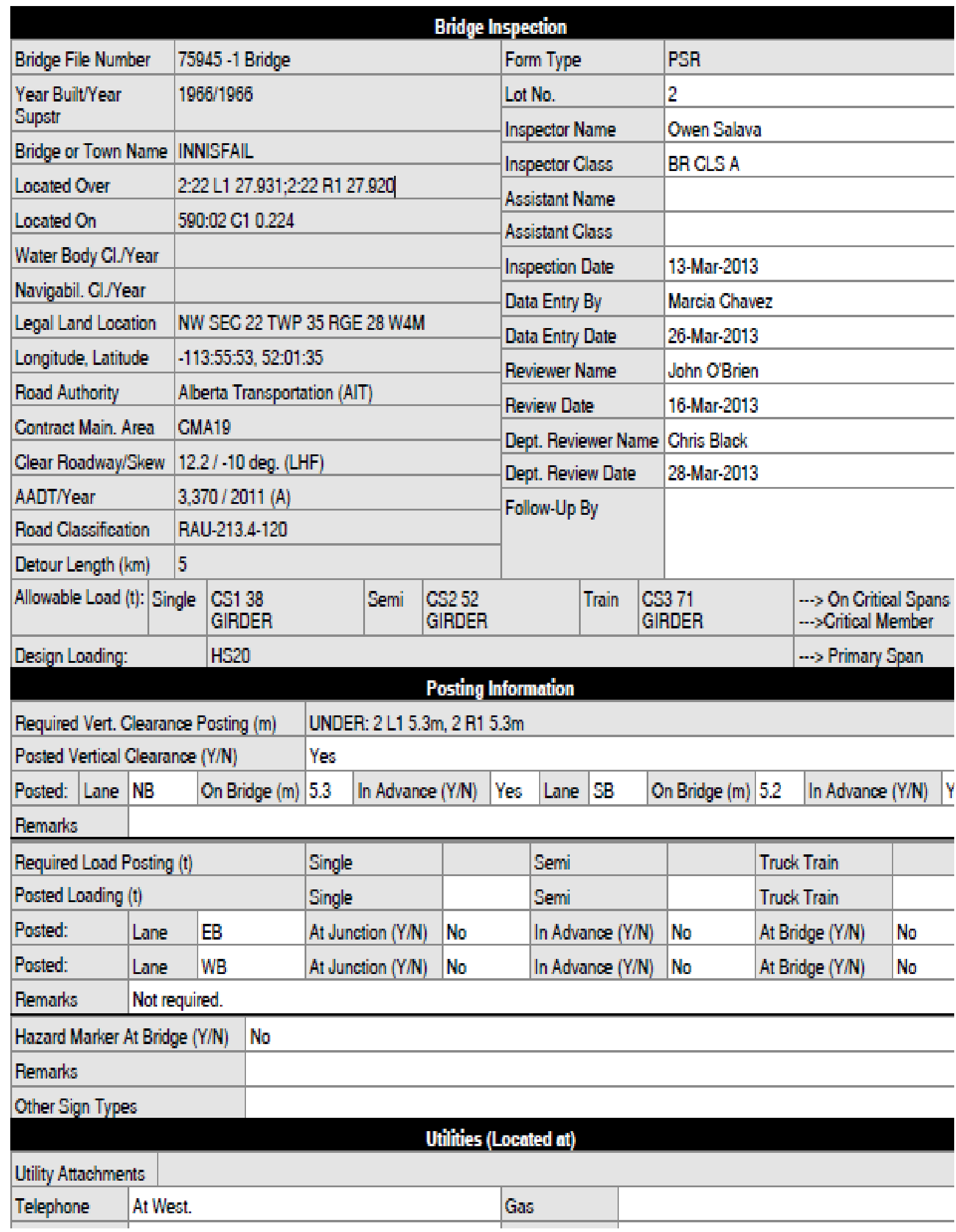

Fig.20. List data of the inspection reports

3- The inspected parts of the bridge model are known on the inspection diagram which assists the observer to find the components Fig.21. 


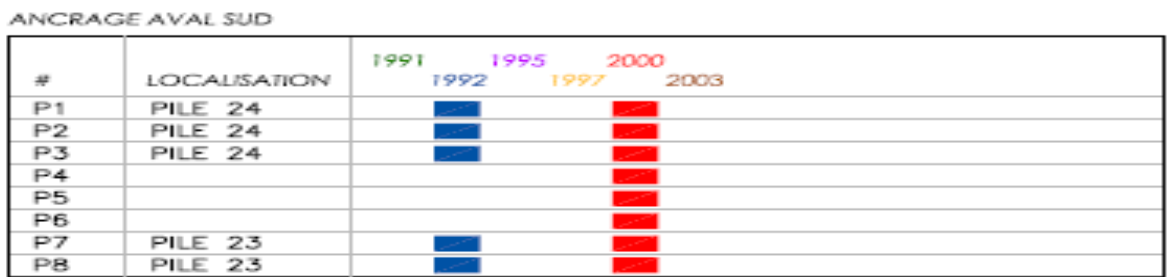

\begin{tabular}{|c|c|c|}
\hline$\#$ & LOCALISATION & $1991_{1992}^{1995}{ }_{1997^{2000}} 2003$ \\
\hline SWAS & PILE 23 & 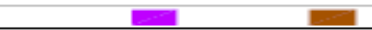 \\
\hline
\end{tabular}
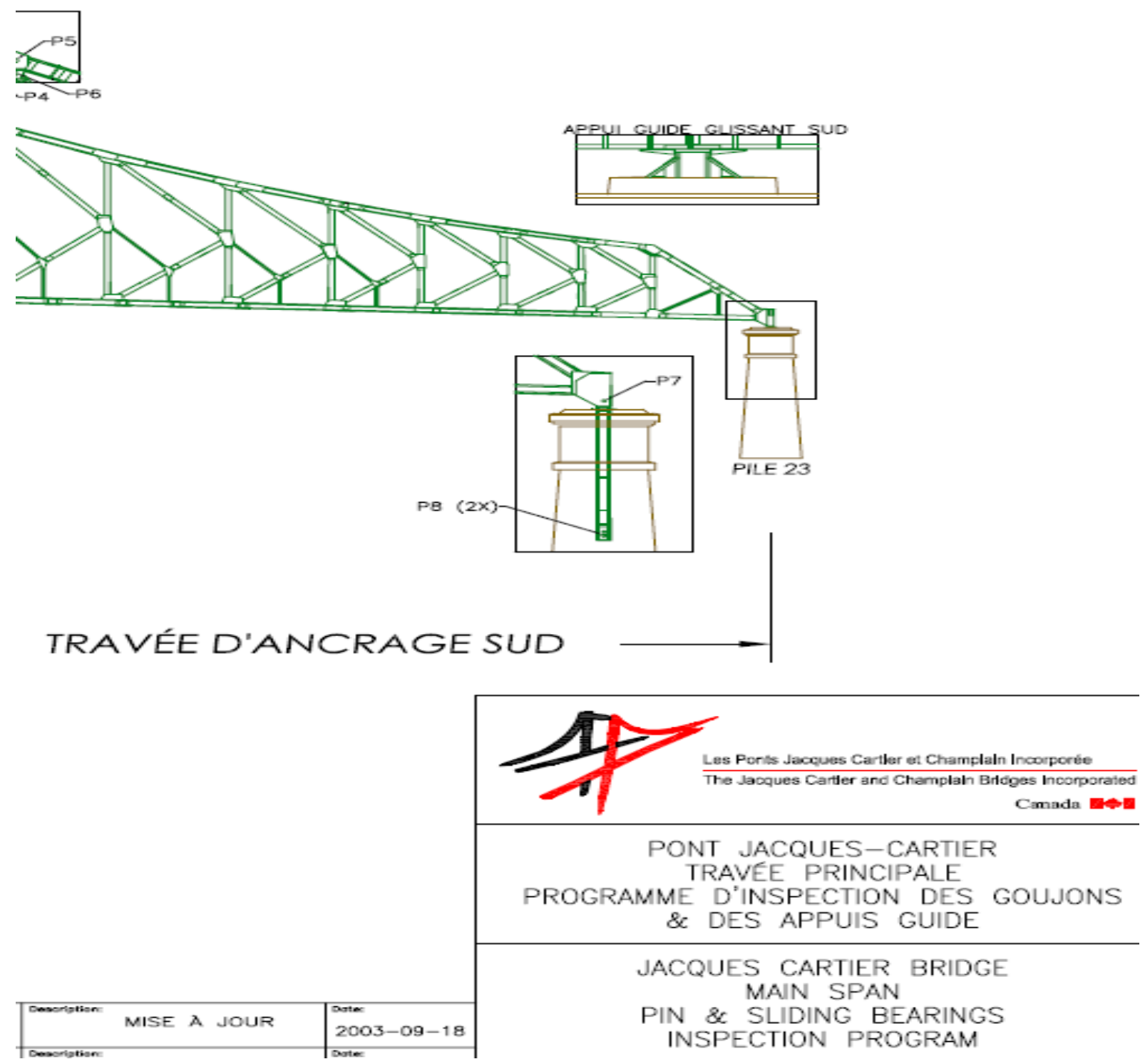

Fig.21. the particular parts are known on the model of the bridge

4- The defect characteristics are measured and compared with the codebook specifications (ex. the loss in surface mortar of the scaling defect defines its severity) Fig.22. 


\begin{tabular}{|c|c|c|c|c|c|c|c|c|}
\hline Defect Type & Description $_{2}$ & Orientation & Severity & $\begin{array}{l}\text { Potential } \\
\text { Location }\end{array}$ & $\begin{array}{l}\text { Locationin } \\
\text { Cast-in-place } \\
\text { Slabs }\end{array}$ & $\begin{array}{l}\text { Location in } \\
\text { Tee beams } \\
\text { and Concrete } \\
\text { girder } \\
\text { bridges }\end{array}$ & $\begin{array}{l}\text { Location in } \\
\text { Concrete } \\
\text { Rigid Frames }\end{array}$ & $\begin{array}{l}\text { Box girder } \\
\text { bridges }\end{array}$ \\
\hline Cracking, flexure & $\begin{array}{l}\text { Cracks which } \\
\text { are caused by } \\
\text { tensile forces }\end{array}$ & Transverse & \multirow[t]{4}{*}{$\begin{array}{l}\text { REINFORCED } \\
\text { CONCRETE(RC) } \\
\text { PRESTRESSED } \\
\text { CONCRETE(PC) } \\
\text { HAIRLINE: RC< } \\
1.6 \mathrm{~mm}, \text { PC< } \\
\text { O.1mm } \\
\text { NARROW: RC< } \\
1.6 \text { to } 3.2 \mathrm{~mm} \text {, } \\
\text { PC< } 0.1 \text { to } \\
0.23 \mathrm{~mm} \\
\text { MEDIUM: } R C< \\
3.2 \text { to } 4.8 \mathrm{~mm} \text {, } \\
\text { PC }<0.25 \text { to } \\
0.76 \mathrm{~mm} \\
\text { WIDE: } \\
\text { RC } \geq 4.8 \mathrm{~mm}, \\
\text { PC } \geq 0.76 \mathrm{~mm}\end{array}$} & Tension Zones & $\begin{array}{l}\text { Midspan } \\
\text { along the } \\
\text { bottom of } \\
\text { the slab, on } \\
\text { top of the } \\
\text { slab over the } \\
\text { piers for } \\
\text { continuous } \\
\text { spans }\end{array}$ & $\begin{array}{l}\text { Midspan } \\
\text { along the } \\
\text { bottom of } \\
\text { the slab, on } \\
\text { top of the } \\
\text { slab over the } \\
\text { piers for } \\
\text { continuous } \\
\text { spans, } \\
\text { Diaphragms }\end{array}$ & $\begin{array}{l}\text { bottom of } \\
\text { the frame } \\
\text { beam at mid- } \\
\text { span, the } \\
\text { base of each } \\
\text { frame leg } \\
\text { (usually } \\
\text { buried), and } \\
\text { the } \\
\text { inside faces } \\
\text { of the frame } \\
\text { legs at mid- } \\
\text { height of } \\
\text { single span } \\
\text { slab frames }\end{array}$ & $\begin{array}{l}\text { The duct } \\
\text { cracks are } \\
\text { normally } \\
\text { locatedon } \\
\text { both sides of } \\
\text { the } \\
\text { longitudinal } \\
\text { or neutral } \\
\text { axis, top } \\
\text { flange at pier } \\
\text { locations and } \\
\text { on the bottom } \\
\text { flange at mid- } \\
\text { span regions, } \\
\text { Anchor blocks } \\
\text { (termination } \\
\text { of the post- } \\
\text { tensioning } \\
\text { tendons) }\end{array}$ \\
\hline Cracking, shear & $\begin{array}{l}\text { Cracks which } \\
\text { are caused by } \\
\text { diagonal tensile } \\
\text { forces }\end{array}$ & Diagonal & & $\begin{array}{l}\text { Shear Zones, } \\
\text { typically web of } \\
\text { a member near } \\
\text { the supports }\end{array}$ & $\begin{array}{l}\text { Bearing } \\
\text { Areas,Shear } \\
\text { Zones } \\
\text { (transverse } \\
\text { cracks } \\
\text { underside } \\
\text { near } \\
\text { supports, } \\
\text { diagonal } \\
\text { cracks on the } \\
\text { sides of the } \\
\text { slab) }\end{array}$ & $\begin{array}{l}\text { Bearing } \\
\text { Areas,Shear } \\
\text { Zones } \\
\text { (transverse } \\
\text { cracks } \\
\text { underside } \\
\text { near } \\
\text { supports, } \\
\text { diagonal } \\
\text { cracks on the } \\
\text { sides of the } \\
\text { slab), } \\
\text { Diaphragms }\end{array}$ & $\begin{array}{l}\text { Bearing } \\
\text { Areas,Shear } \\
\text { Zones(near } \\
\text { the supports } \\
\text { where the } \\
\text { frame beams } \\
\text { or slab meet } \\
\text { the frame } \\
\text { legs or } \\
\text { abutments) }\end{array}$ & $\begin{array}{l}\text { Bearing Areas, } \\
\text { girder ends } \\
\text { and sections } \\
\text { close to piers, } \\
\text { Deviation } \\
\text { Blocks, } \\
\text { Internal } \\
\text { Diaphragms }\end{array}$ \\
\hline $\begin{array}{l}\text { Cracking, } \\
\text { temperature }\end{array}$ & $\begin{array}{l}\text { Cracks which } \\
\text { are caused by } \\
\text { the thermal } \\
\text { expansion and } \\
\text { contraction of } \\
\text { the concrete }\end{array}$ & $\begin{array}{l}\text { Transverse } \\
\text { and } \\
\text { longitudinal }\end{array}$ & & $\begin{array}{l}\text { Concrete Deck } \\
\text { and all concrete } \\
\text { components } \\
\text { which has been } \\
\text { prevented from } \\
\text { contacting }\end{array}$ & $\begin{array}{l}\text { Near } \\
\text { supports } \\
\text { when a } \\
\text { bearing } \\
\text { problem is } \\
\text { detected }\end{array}$ & & & \\
\hline $\begin{array}{l}\text { Cracking, } \\
\text { shrinkage }\end{array}$ & $\begin{array}{l}\text { Cracks which } \\
\text { are caused by } \\
\text { shrinkage of } \\
\text { concrete caused } \\
\text { by the curing } \\
\text { process in } \\
\text { plastic } \\
\text { shrinkage }\end{array}$ & $\begin{array}{l}\text { All directions, } \\
\text { short and } \\
\text { irregular } \\
\text { shapes }\end{array}$ & & $\begin{array}{l}\text { All concrete } \\
\text { components } \\
\text { after curing } \\
\text { process }\end{array}$ & & & & \\
\hline $\begin{array}{l}\text { Cracking, mass } \\
\text { concrete }\end{array}$ & $\begin{array}{l}\text { Cracks which } \\
\text { are caused by } \\
\text { thermal } \\
\text { gradients in } \\
\text { massive } \\
\text { sections }\end{array}$ & All directions & $\begin{array}{l}\text { Typically do not } \\
\text { significantly } \\
\text { affect } \\
\text { thestructural } \\
\text { strength }\end{array}$ & $\begin{array}{l}\text { Massive } \\
\text { sections e.g. } \\
\text { Concrete Deck } \\
\text { and large } \\
\text { girders }\end{array}$ & & & & \\
\hline Scaling & $\begin{array}{l}\text { Gradual and } \\
\text { continuing loss } \\
\text { of surface } \\
\text { mortar and } \\
\text { aggregate }\end{array}$ & & $\begin{array}{l}\text { Light- loss of } \\
\text { surface mortar } \\
\text { up to } 6 \mathrm{~mm}(1 / 4 \\
\text { inch) deep, with } \\
\text { surface exposure } \\
\text { of coarse } \\
\text { aggregates } \\
\text { Medium scale- } \\
\text { loss of surface } \\
\text { mortar from } 6 \text { to } \\
13 \mathrm{~mm}(1 / 4 \mathrm{inch} \\
\text { to } 1 / 2 \text { inch) deep, } \\
\text { with mortar loss } \\
\text { between the } \\
\text { coarse } \\
\text { aggregates }\end{array}$ & $\begin{array}{l}\text { Concrete Deck, } \\
\text { harsh } \\
\text { environments } \\
\text { which cause } \\
\text { chemical } \\
\text { breakdown of } \\
\text { the cement } \\
\text { bond }\end{array}$ & $\begin{array}{l}\text { Concrete } \\
\text { Deck, Areas } \\
\text { exposed to } \\
\text { traffic, Areas } \\
\text { near bearings }\end{array}$ & $\begin{array}{l}\text { Concrete } \\
\text { Deck, Areas } \\
\text { exposed to } \\
\text { traffic, Areas } \\
\text { near bearings }\end{array}$ & $\begin{array}{l}\text { Concrete } \\
\text { Deck, Areas } \\
\text { exposed to } \\
\text { traffic, Areas } \\
\text { near bearings }\end{array}$ & $\begin{array}{l}\text { Concrete } \\
\text { Deck, Areas } \\
\text { exposed to } \\
\text { traffic ,Areas } \\
\text { near bearings }\end{array}$ \\
\hline
\end{tabular}

Fig.22. Sample of concrete bridge defects (Adapted from [39, 40]) 
5- The bridge defect is detected and determined its properties in the modeling software program, as Fig.23 the scaling defect is defined and modeled in RiSCAN software.

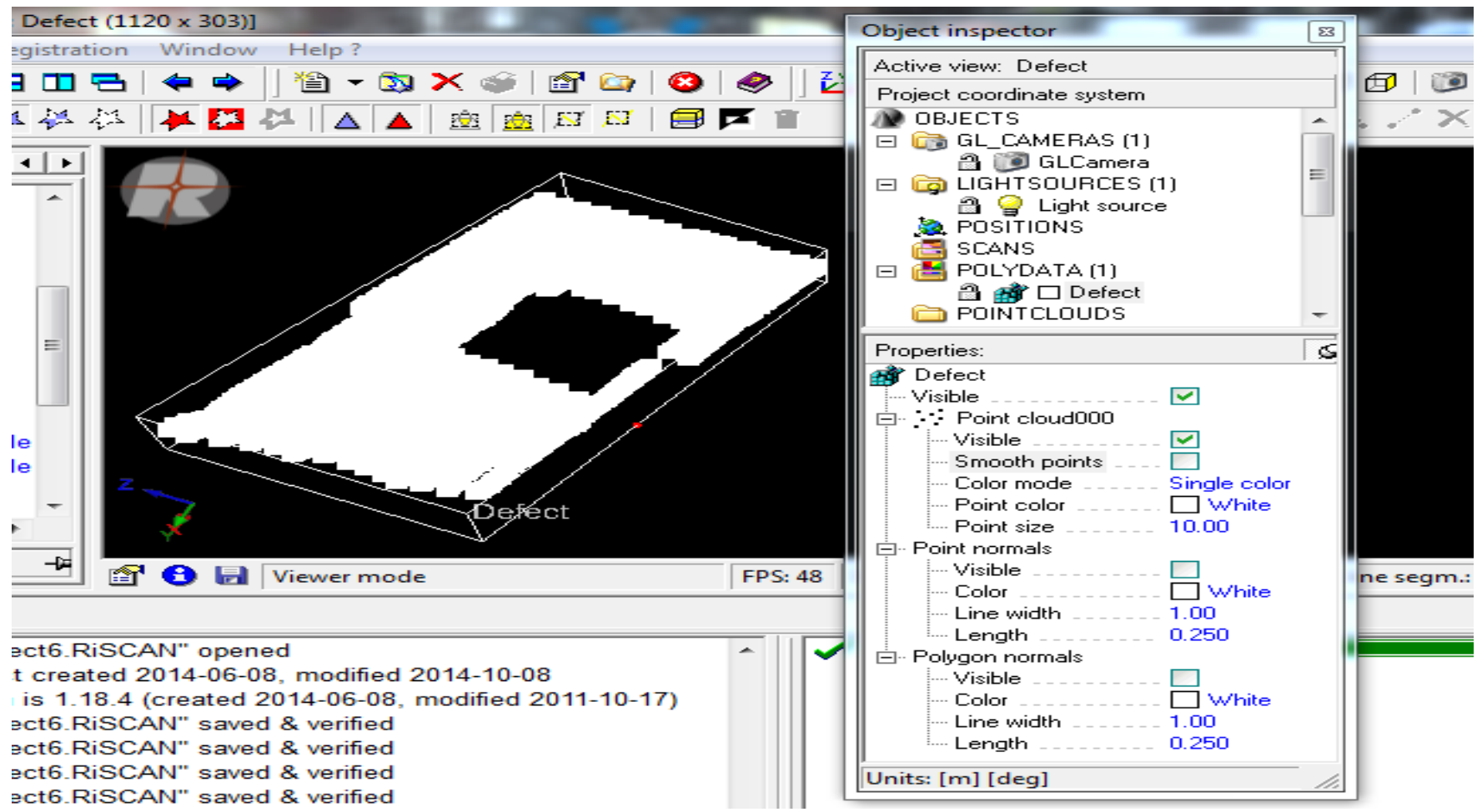

Fig.23. The Bridge scaling defect is modeled in the software

6- The modeled defect is modified to similar its characteristics with the real defect. The defect type determines its characteristics (ex., the characteristics of the scaling defect are the shape, area, depth, orientation, etc.).

7- The modeled defect is registered on its actual pose and orientation in the 3D model of the bridge, as Fig.24, The scaling defect is aligned in its place on the bridge.

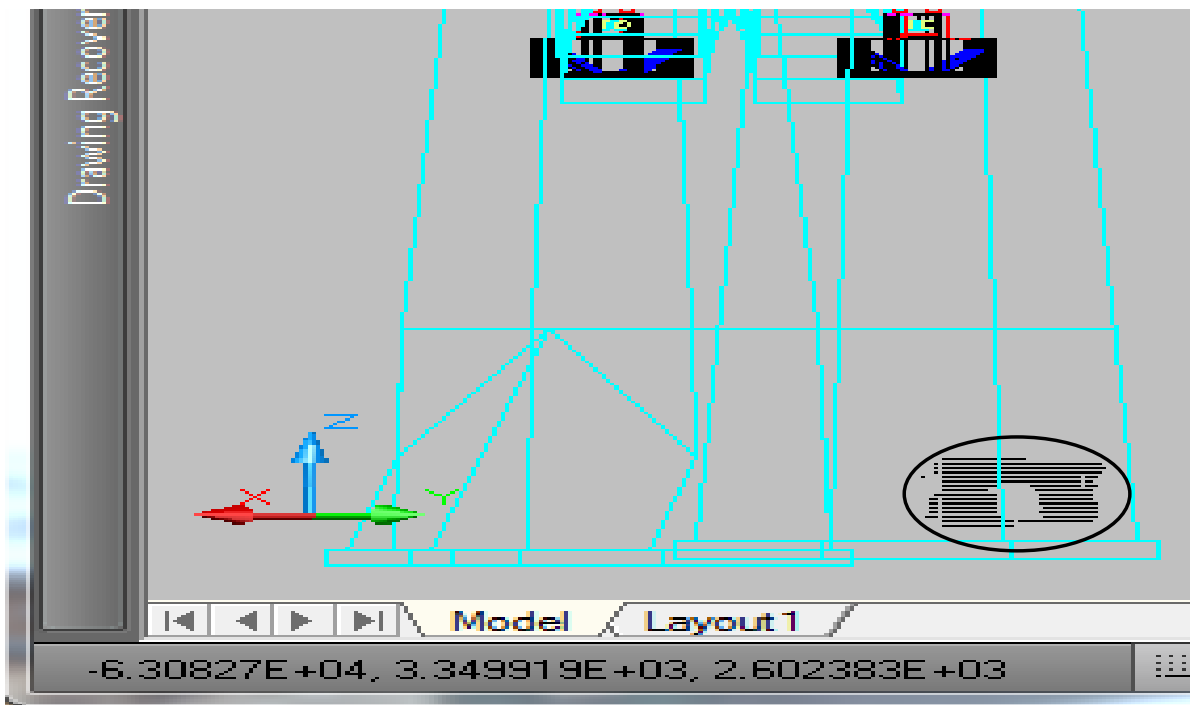

Fig.24. The modeled defect is registered on the 3D model of the bridge.

8- The inspection codebook characteristics of the defect are stored in the storage area of the BrIM. 


\section{4- Conclusion}

In this paper, the method of generating defects information models is enhanced to recover BIM objects from 3D range surveying data by IR (Infra Red) cameras or Laser Scanners sensors for object defects inspections. The photograph of the object defect have limited distances (are $0.8-9 \mathrm{~m}$ in case of IR cameras) between the sensor station and the defect plane, but with more flexible distances in case of laser scanners sensors.

Mathematical model of photography of the object defect pose and transformations that through virtual tilted plane as the general case to the range sensor image were deduced. This resembles the actual photographs taken by the sensors mounted at anywhere and pointed towards any parts of the building. The resulting formulas for defect coordinates transformations $\boldsymbol{x}, \boldsymbol{y}$ and $\boldsymbol{z}$ were deduced. Inverse formulas of the defect are established which are used to find the coordinates of the defect plane in terms of the defect image coordinates.

This study proposes enhancement the building defects inspection by simplification the method of information visualization and adding 3D LIDAR (Laser or Range camera) structural defects observations to the BrIM (Bridge Information Model). Standing on the method, the Defect Information Model (DIM) is in its real shape, which decreases the difficulty and saves the time of modeling the irregular shapes of the defects.

To show the feasibility of the proposed methodology, a system is developed to carry out the research requirements using the technique discussed in previous section to realize the case study purposes. The advantage of this technique is the flexibility it provides to handle complex defects. The proposed approach is validated through the case study on the inspection data and modeling the defects in the Jacques Cartier Bridge in Canada.

\section{5- Acknowledgments}

The first author would like to thank MOHE (Egyptian Ministry of High Education) for the research funds and Concordia University in Canada for the research facilities, and appreciate the helps of Prof Dr Abbas Mansour, the president of South Valley University., Egypt, Prof Dr Gamal Tag, the dean of Qena Faculty of engineering, Prof Dr Hamdan Okasha, the head of the civil dept., and also Prof Dr Hesham Ismaiel, special thanks are owed to all Professors and Mates in Qena Faculty of engineering, and many Professors and Mates in EJUST, Egypt, and He would like to thank the helps of Prof Dr Walaa Sheta, the dean of the informatics institution in MUCSAT, and Prof Dr Bayomee Abd Al-Rahman, the head of the dept., and also Eng. Dina Hafiz in MUCSAT, Egypt. 


\section{6- References}

[1] Gairns C. "Development of a semi-automated system for structural deformation monitoring using a reflectorless total station", M.Sc.E.- Thesis, University of New Brunswick, Canada (2008).

[2] Ismaiel H.A.H., Makhloof A.A., Mahmoud A.A. and Galal A.A.: "Monitoring System of Cracks along Qena-Safaga Road Using Total Station, Eastern Desert, Egypt", Conference program and abstracts, the second symposium on the geological resources in the Tethys realm, Aswan, Egypt, 5-8 January (2013).

[3] Burland J.B., and Wroth C.P., "Settlement of buildings and associated damage" In: The British geotechnical society's conference on the settlement of structures. Cambridge, 1974: 611-54.

[4] Chung H.W., "Assessment and classification of damages in reinforced concrete structures". Concrete Int, 1994; 16:55-9.

[5] Marazzi F, Tagliabue P, and Corbani F.M., "Traditional vs. innovative structural health monitoring of monumental structures: a case study". Struct Contr Health Monit; 2011, 18:430-49.

[6] Laflamme S., Kollosche M., Connor J.J., and Kofod G., "Soft capacitive sensor for structural health monitoring of large-scale systems". Struct Contr Health Monit; 2012, 19:70-81.

[7] Debra F. L., Linh T., Hamish C., and Manmeet S. "Crack detection limits in unit based masonry with terrestrial laser scanning" NDT\&E International 62, (2014), 66-76.

[8] Abdelhafiz A.," Integrating Digital Photogrammetry and Terrestrial Laser Scanning" PhD thesis, Munchen, Germany, 2009.

[9] El-Omari S., and Moselhi O., "Integrating 3D laser scanning and photogrammetry for progress measurement of construction work", Automation in Construction 18 (2008) 19.

[10] Adhikari, R. S., Moselhi, O., and Bagchi, A.. "Image-based retrieval of concrete crack properties for bridge inspection." Automation in Construction, 39(0), 2014, pp.180-194.

[11] Web site1:“Montreal-is-falling-down”, (2014), Photos by Roger Lemoyne ,Montreal, Canada, 2014, http://www.macleans.ca/news/canada/montreal-is-falling-down/.

[12] Maißner E. M., and Aahs A., Modul Bauforschung Workshop, 2010/11 Vienna University of Technology, in Cooperation with the Cairo University and the Assiut University, December 2010.

[13] Sedek M., A. Abdelhafiz, "Photogrammetry and Laser Scanning for Barron Palace Building, Barron Workshop, Egypt" Internal paper, 2012.

[14] Atkinson K. (ed.), Close range Photogrammetry and Machine Vision, 1996, (Chapter 9).

[15] Fraser, C., "Digital camera self-calibration", ISPRS J. of Photogrammetry and Remote Sensing, 52(4), pp. 149-159, 1997.

[16] Triggs, B., McLauchlan, P. F., Hartley, R. and Fitzgibbon, A., 2000, Bundle adjustment - a modern synthesis. Proceedings of the International Workshop on Vision Algorithms, Corfu, Greece, 21st to 22nd September 1999. Springer, Berlin. Lecture Notes in Computer Science, Vol. 1883, 386 pages, pp. 298-372.

[17] Bernardini F., and Rushmeier H., 2002, "The 3D model acquisition pipeline", Computer Graphics Forum 21 (2) (June 2002) 149-172.

[18] Staiger R., 2003, “Terrestrial Laser Scanning Technology, Systems and Applications", in 2nd FIG Regional Conference, Sheraton Marrakech, Marrakech, Morocco, December 2-5 (2003). 
[19] Tang P., Huber D., Akinci B., Lipman R., and Lytle A., 2010, "Review Automatic reconstruction of as-built building information models from laser-scanned point clouds": A review of related techniques, Automation in Construction 19 (2010) 829843.

[20] MESA 2014, SR4500 User Manual, MESA IMAGING, Version 3.0.

[21] Sedek M., Abdel-A'L M., Youssef A., and Farrag A. "Coordinates Transformations of the Panoramic Photographs onto a Sphere" Journal of Engineering Science, Assiut University, Vol.37, No.1, 2009, pp.17-27, Egypt.

[22] Youssef A., "Triple projection of a topographic surface from an external perspective center", Ph.D. Thesis, Civil Engineering Department, Faculty of Engineering, Assiut University, Assiut, Egypt, 1993.

[23] Sedek M., Abdel-A'L M., Youssef A., and Farrag A. "Coordinates Transformations of the Panoramic Photographs onto a Sphere" Master thesis, Assiut University, Assiut, Egypt, 2009.

[24] El-Hakim, S., Gonzo, L., Picard, M., Girardi, S., and Simoni, A., 2003b: "Visualization of frescoed surfaces: Buonconsiglio Castle - Aquila Tower," "Cycle of the Months". IAPRS, Vol. XXXIV, part 5/W10 (on CD-Rom), 2003.

[25] Grammatikopoulos, L., Kalisperakis, I., Karras, G., Kokkinos, T., and Petsa, E., "Automatic Multi-Image Photo-texturing of 3D Surface Models Obtained With laser Scanning". CIPA International Workshop on "Vision Techniques Applied to the Rehabilitation of City Centers", Lisbon, 25-27 October 2004.

[26] Abdelhafiz A., and Niemeier W., "Automatic Texturing For Laser Scanner Meshes". $8^{\text {th }}$ Conf. Optical 3-Ds Measurement Techniques, Zurich, Switherland, 9-12 July 2007.

[27] Mailhot and Busuioc, "Application of long range 3d laser scanning for remote sensing and monitoring of complex bridge structures", the 7th International Conference on Short and Medium Span Bridges, Montreal, Canada, 2006.

[28] Fritsch, D., "3D Building Visualisation - Outdoor and Indoor Applications". Photogrammetric Week '03, Ed. D. Fritsch, Wichmann, Heidelberg, 2003, pp. 281-290. Also in: Geo-Information-Systems, 9/2003, pp. 26-32.

[29] Fritsch, D., and Kada, M., "Visualization Using Game Engines. International Archives Photogrammetry and Remote Sensing" (IAPRS), Vol. 35, Part B. Istanbul, 2004.

[30] Hammad, A., Zhang, C., Hu, Y. and Mozaffari, E. "Mobile model-based bridge lifecycle management systems", Journal of Computer-Aided Civil and Infrastructure Engineering, Vol. 21 No. 7, (2006), pp. 530-547.

[31] Bisby, L.A. and Briglio, M.B. "ISIS Canada Educational Module No. 5: An Introduction to Structural Health Monitoring", ISIS Canada, (2004). pp.3.

[32] Gagnon M., Gaudreault V. and Overton D. "Age of Public Infrastructure: A Provincial Perspective" Minister responsible for Statistics Canada, (2008).

[33] Industry Canada. Industry Canada - Gross Domestic Product Transportation and Warehousing, 2013 (NAICS, pp 48-49). Retrieved on Oct 2013, http://www.ic.gc.ca/cis-sic/cis-sic.nsf/IDE/cis-sic48-49vlae.html.

[34] PJCCI, The official website of The Jacques Cartier and Champlain Bridges Incorporated. (2004), http://www.pjcci.ca/.

[35] Zaki, A., R. and Mailhot, G., "Deck Reconstruction of Jacques Cartier Bridge Using Pre-cast Pre-stressed High Performance Concrete Panels", PCI Journal, SeptemberOctober, 2003, 2-15.

[36] Hu, Y., and Hammad, A. "Location-based mobile bridge inspection support system." Proceedings of the 1st CSCE Specialty Conference on Infrastructure Technologies, Management and Policy, Toronto, Canada, FR(130) (2005), pp.1-10. 
[37] Zhang, C. and Hammad, A. "Spatio-Temporal Issues in Infrastructure Lifecycle Management Systems", Proceedings of the 1st CSCE Specialty Conference on Infrastructure Technologies, Management and Policy, Toronto, Canada (2005).

[38] Danial M., and Hammad A., , "Framework for Integrating Bridge Inspection Data with Bridge Information Model", Master thesis, Concordia Institute for Information Systems Engineering, Concordia University, Montreal, Quebec, Canada, 2014.

[39] BIRM, "Bridge Inspector's Reference Manual", Volume 2, U.S. Department of Transportation, (2012).

[40] BIM Reference Manual, "Bridge Inspection and Maintenance System Reference Manual" Version 3.0, Alberta, Alberta Infrastructure and transportation. (2007). 